\title{
Energy Harvesting From Human and Machine Motion for Wireless Electronic Devices
}

\section{Practical miniature devices are becoming available for harnessing kinetic energy as a substitute for batteries in medical, and many other, low power applications.}

\author{
By Paul D. Mitcheson, Member IEeE, Eric M. Yeatman, Senior Member IEeE, \\ G. Kondala Rao, Student Member IEEe, Andrew S. Holmes, Member IEEE, And \\ Tim C. Green, Senior Member IEEE
}

\begin{abstract}
Energy harvesting generators are attractive as inexhaustible replacements for batteries in low-power wireless electronic devices and have received increasing research interest in recent years. Ambient motion is one of the main sources of energy for harvesting, and a wide range of motionpowered energy harvesters have been proposed or demonstrated, particularly at the microscale. This paper reviews the principles and state-of-art in motion-driven miniature energy harvesters and discusses trends, suitable applications, and possible future developments.
\end{abstract}

KEYWORDS | Energy scavenging; micropower generator; micropower supply; vibration-to-electric energy conversion

\section{INTRODUCTION}

Wireless power supplies have the same advantages for electronic devices as do wireless communications: they allow portability, and even for non-portable applications they reduce installation costs by eliminating wiring. The latter feature is particularly important where sources of wired power are not locally available. For this reason, improved wireless power supplies are increasingly sought after as electronic systems proliferate. Batteries in their various forms have so far been the primary solution; however, they frequently dominate the size, and sometimes

Manuscript received January 8, 2008; revised June 4, 2008. This work was supported by the Engineering and Physical Sciences Research Council and the European Commission.

The authors are with the Department of Electrical and Electronic Engineering, Imperial College London, London, U.K. (e-mail; paul.mitcheson@imperial.ac.uk).

Digital Object Identifier: 10.1109/JPROC.2008.927494 the cost, of the devices in question and introduce an unwanted maintenance burden of replacement or recharging. Alternative power sources that overcome these limitations are thus highly desirable. The possible approaches to this challenge are to use local energy supplies with higher capacity, to deliver power wirelessly from an active source introduced for this purpose, or to extract power from ambient sources in some way.

Improving the energy density (and other features such as cost, number of charging cycles, and power density) of batteries has been, and continues to be, a major research field. Battery storage densities have increased substantially in the last decades, with lithium-ion batteries in particular now having typical capacities of about $160 \mathrm{~W} \cdot \mathrm{h} / \mathrm{kg}$ [1], [2], i.e., about $1 \mathrm{~kJ} / \mathrm{cc}$. Hydrocarbon fuels, however, offer energy densities more than an order of magnitude above even the theoretical potential of lithium-ion batteries, for example, $8 \mathrm{~kW} \cdot \mathrm{h} / \mathrm{kg}$ for methanol [1]. Of course the use of fuel requires a conversion mechanism (which will also impact on the system volume). Small-scale converters investigated to date include miniature turbine engines [3], [4] and a micro Stirling-engine [5], but the most researched and most promising to date are micro fuel cells [6], [7]. Fuel-based power sources naturally do not overcome the recharging requirement of batteries, but rather replace it with a (less frequent) refuelling requirement. Capacitors are another possible finite energy store; however, although some advantage may be obtained by their much higher power densities and cycle lifetimes compared to batteries, their energy densities remain relatively low, with theoretical limits around $10 \mathrm{~W} \cdot \mathrm{h} / \mathrm{kg}$ [8]. Conversely, radioactive materials provide a possible power source with low power density but long lifetimes, and miniature power 
supplies based on these have also been demonstrated [9]. More comprehensive reviews of portable power sources are presented by Roundy et al. in [2] and [10] and Fukunda and Menz in [11].

Power can be actively delivered continuously, periodically, or on demand, using far-field electromagnetic radiation [12] or near-field coupling [13], [14]. Such power supplies require the use of infrastructure in addition to the powered device itself, and of course the supplying source must in turn be supplied with power. However, this can be a useful solution when the device to be powered is inaccessible (e.g., implanted sensors) or when power is only needed when information is extracted (e.g., passive RF identification (RFID) tags).

Extracting power from ambient sources is generally known as energy harvesting, or energy scavenging. This approach has recently attracted a great deal of interest within both the academic community and industry, as a potential inexhaustible source for low-power devices. Generally energy harvesting suffers from low, variable, and unpredictable levels of available power. However, the large reductions in power consumption achieved in electronics, along with the increasing numbers of mobile and other autonomous devices, are continuously increasing the attractiveness of harvesting techniques. Consequently, the amount of research in the field, and the number of publications appearing, have risen greatly. Special issues on energy harvesting have appeared, for example, in IEEE Pervasive Computing Magazine [15] and the Intelligent Materials Systems and Structures Journal [16].

The sources of energy available for harvesting are essentially of four forms: light, radio-frequency (RF) electromagnetic radiation, thermal gradients, and motion, including fluid flow. All have received attention, in varying degrees. Solar cells are the most mature and commercially established energy-harvesting solution [17]-[19], and are of course exploited across a wide range of size scales and power levels. While cost is a key parameter for large-scale photovoltaic generation, at the small scale of portable electronic devices this is less of an issue, and light availability is instead the key limitation. A wide range of work has also been presented on small-scale thermoelectric generation [20]-[23], and successful applications include the Seiko Thermic watch. ${ }^{1}$ Temperature differences tend to be small over the miniature size scale associated with most harvesting applications, which leads to poor thermodynamic efficiency, but useful power levels can be captured from differences as little as a few degrees celsius. Ambient RF has also received some attention [13], [24], [25], although availability of significant power levels is again an issue [26], and efficient extraction using devices much smaller than the radiation wavelength is another key challenge. As an adjunct to the four main sources for harvesting, fuel-based generation using ambient fluids as

${ }^{1}$ http://www.seikowatches.com. fuel, specifically human bodily fluids, has also been reported [27].

The relative advantages and disadvantages of the different sources for energy harvesting have been discussed thoroughly by various authors [2], [10], [28]-[31]; consequently, the arguments will not be repeated here in detail. The general opinion from the literature is that while each application should be evaluated individually with regards to finding the best energy-harvesting method, kinetic energy in the form of motion or vibration is generally the most versatile and ubiquitous ambient energy source available. The purpose of this paper is to review the principles, achievements, future potential, and possible applications of motion-based energy harvesting.

\section{APPLICATIONS FOR MOTION-BASED ENERGY HARVESTING}

\section{A. Wireless Sensor Networks}

Traditionally, health care has concentrated upon shortterm treatment rather than long-term monitoring and prevention [32]. However, many chronically ill patients could have a significant increase in quality of life and life expectancy if certain biological signs could be continually monitored and controlled during their daily lives. Three examples illustrate the potential of this approach: continually monitoring blood pressure in patients with hypertension can significantly increase medication compliance [33]; real-time processing of electrocardiograph traces can be very effective at revealing early stages of heart disease [34]; and closed-loop control of insulin administration for diabetic patients would significantly reduce the risk of hypoglycemia [35]. Monitoring can also allow better targeting of medicines, reducing costs and unwanted side-effects. In order to achieve these benefits, many types of body-mounted or implanted medical devices are desired [36].

Implantable or wearable devices will only significantly increase quality of life if they are unobtrusive to the patient [37], [38] in terms of both use and maintenance. It is especially important to eliminate maintenance for implantable devices, for which replacement of the power source in particular must be avoided [39]. While some implanted sensors can be totally passive and used in conjunction with active equipment when a measurement is needed [40], and some active devices could be powered up occasionally by wireless energy transfer, many require a continuous source of electrical power [36]. Ideally, all implantable medical devices would have a power-supply lifetime as long as the required operational lifetime, thus keeping surgery, and cost, to a minimum. This vision of unobtrusive, automated health care [41] using wearable and implanted wireless medical devices is the main focus of a new and fast-growing multidisciplinary research area, that of the body sensor network (BSN) [42], [43]. In general, 


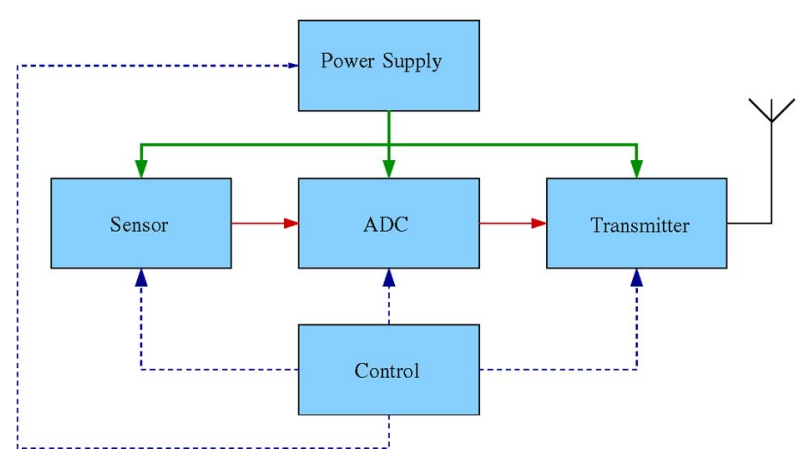

Fig. 1. Basic wireless sensor arrangement.

the tiny size of information-processing and RF integrated circuits means that batteries dominate the size of devices that require long operating times [2], [35], [44], such as BSN nodes. However, the continual evolution of solidstate electronics, combined with new circuit design techniques, has led to vast reductions in power consumption, as well as size, for circuits required to perform given functions. This combination of low power requirements, tight size constraints, and the need to eliminate maintenance makes BSN a particularly attractive application for energy harvesting.

The BSN is a specific instance of a more general topic, the wireless sensor network (WSN) [45], [46]. The general wireless sensor network concept is that of deploying many small, inconspicuous, self-contained sensor nodes, often referred to as motes, into an environment to collect and transmit information, and possibly provide localized actuation. Other than medical applications, potential uses for WSNs include structural monitoring of buildings [47]; status monitoring of machinery; environmental monitoring of domestic environments to make them more comfortable [48], [49]; military tracking [49]; security; wearable computing; aircraft engine monitoring [50]; and personal tracking and recovery systems [51]. As with BSNs, many application areas will only be attractive for WSN use if motes can be powered by an inexhaustible energy source, such as harvested energy.

Fig. 1 shows a block diagram of the signal and processing elements of a wireless sensor mote capable of sending the data to a remote location for processing. The minimum power requirements of such a device can be estimated using a mixture of currently available off-the-shelf technology, and devices which are the current state-of-the-art in research. As an example, consider the following three elements.

1) Sensor: The STLM20 temperature sensor from ST Micro [52] draws typically $12 \mu \mathrm{W}$ quiescent power at $2.4 \mathrm{~V}$ supply voltage.

2) $A D C$ : An ADC reported by Sauerbrey et al. [53] has power dissipation below $1 \mu \mathrm{W}$ for 8 bit sampling at $4 \mathrm{kS} / \mathrm{s}$.
3) Transmitter: IMEC recently announced an IEEE 802.15.4a standard-compliant ultra-wide-band transmitter [54] with a power consumption of only $0.65 \mathrm{~nJ}$ per 16 chip burst operating at a low duty cycle.

The required data rates for biomonitoring applications tend to be quite low due to the relatively low rates of change of the variables [44]. One of the highest rates required is for heartbeat monitoring, at around 100 samples/s. If this is combined with a resolution of 10 bits, then the data rate is $1 \mathrm{kbps}$, which, if the transmitter power quoted can be scaled to such low data rates, requires only $0.65 \mu \mathrm{W}$. This suggests a total power consumption for the sensor node of $10-20 \mu \mathrm{W}$, or even $1-2 \mu \mathrm{W}$ or less if the other components are also duty cycled. There would be some extra overhead for power-processing interface and timing circuitry, but it is reasonable to estimate that the total device power consumption could ultimately be reduced to a few $\mu \mathrm{W}$, at least for this biosensor application. As discussed below, this is within achievable levels for energy harvesters of modest (below $1 \mathrm{cc}$ ) size, even when harvesting lowfrequency body motion. It should be noted that while the power values quoted above are achievable, currently available wireless sensor nodes have substantially higher levels of power consumption.

\section{B. Other Applications}

Limited battery life is a significant inconvenience for most portable electronic devices, so target applications for energy harvesting are primarily limited by the feasibility of harvesting in each case. This feasibility depends mainly on four factors: the typical power consumption of the device; the usage pattern; the device size (and thus the acceptable harvester size); and the motion to which the device is subjected (for motion harvesting specifically). For example, laptop computers are poor candidates for harvesting: although they are relatively large, they have high power consumption (10-40 W), and their typical usage patterns comprise long periods (tens of minutes to hours) of continuous use, with idle periods mostly spent in a low-motion environment. Even if harvesting is used to supplement rather than replace batteries, the added battery life is likely to be marginal at best for most users.

Mobile telephones (cell phones) are a somewhat more attractive target, as they tend to be carried on the body for much of the time, thus experiencing regular motion while only being used (other than in low-power monitoring mode) for relatively short periods. Of course the relative amounts of motion and usage are highly dependent on the user. The power levels during calls are typically a few watts, and this is likely to reduce to some extent with advances in the relevant technologies. However, space is very much at a premium in handsets, and energyharvesting power densities reported to date for body motion sources, as reviewed below, are well below the levels at which this application becomes feasible. For other 
handheld devices, such as mp3 players and personal organizers, the considerations are similar to those for phones, with some differences in power requirements and usage patterns.

Thus, wireless sensors would appear to be the primary application area for motion harvesting, at least in the short term. However, niche or unexpected applications are likely to appear as well. One that has already been successfully exploited is the harvesting of mechanical power in a finger-actuated light switch to power a transmitter circuit that relays the switching signal to a remote lighting module [55].

\section{MOTION-DRIVEN ENERGY HARVESTERS: OPERATING PRINCIPLES}

\section{A. Introduction}

Motion-driven microgenerators fall into two categories: those that utilize direct application of force and those that make use of inertial forces acting on a proof mass. The operating principle of a direct-force generator is shown in Fig. 2. In this case, the driving force $f_{d r}(t)$ acts on a proof mass $m$ supported on a suspension with spring constant $k$, with a damping element present to provide a force $f(\dot{z})$ opposing the motion. If the damper is implemented using a suitable transduction mechanism, then in opposing the motion, energy is converted from mechanical to electrical form. There are limits of $\pm Z_{l}$ on the displacement of the mass, imposed by device size. Direct force generators must make mechanical contact with two structures that move relative to each other, and can thus apply a force on the damper.

The operating principle of inertial microgenerators is shown in Fig. 3. Again a proof mass is supported on a suspension, and its inertia results in a relative displacement $z(t)$ when the frame, with absolute displacement $y(t)$, experiences acceleration. The range of $z(t)$ is again

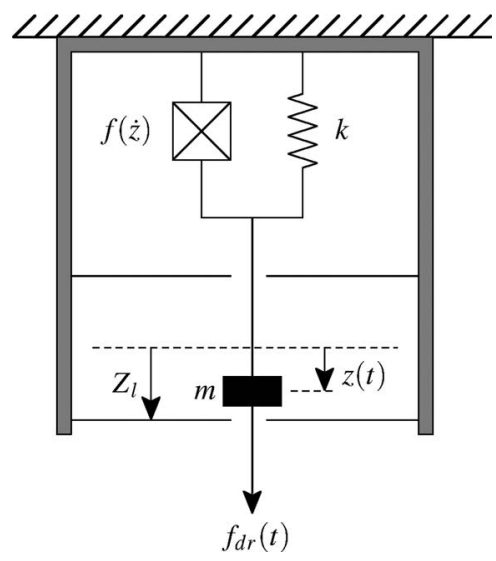

Fig. 2. Generic model of direct-force generator.

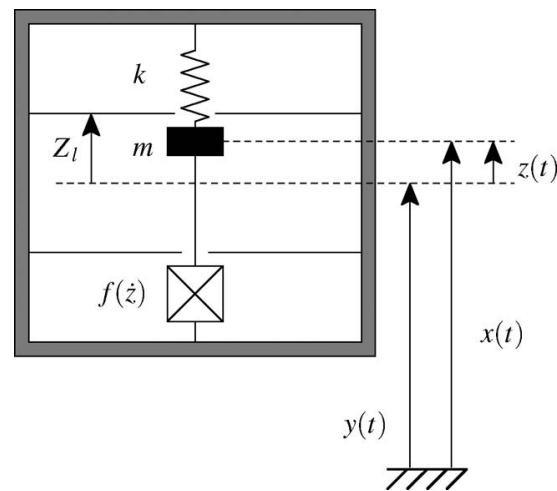

Fig. 3. Generic model of inertial generator.

$\pm Z_{l}$. Energy is converted when work is done against the damping force $f(\dot{z})$, which opposes the relative motion. Inertial generators require only one point of attachment to a moving structure, which gives much more flexibility in mounting than direct-force devices and allows a greater degree of miniaturization.

In order to generate power, the damper must be implemented by a suitable electromechanical transducer. This can be done using one of the methods described below.

\section{B. Transduction Methods}

In conventional, macroscale engineering, electrical generators are overwhelmingly based on electromagnetic transduction. In small-scale energy harvesting, two main additional techniques are added. Electrostatic transduction, which is both impractical and inefficient for large machines, becomes much more practical at small size scales and is well suited to microelectromechanical (MEMS) implementation. Piezoelectric transduction is generally impractical for rotating systems but is well suited to the reciprocating nature of the motions typically used for harvesting (e.g., vibration).

Rotating electromagnetic generators are in common use from power levels of a few watts (brushless dc domestic wind turbine systems) to several hundred megawatts (synchronous machines in power plants). It is possible to implement the damper of a microgenerator using the same principle, i.e., that described by Faraday's law of induction, as illustrated in Fig. 4. A change of magnetic flux linkage with a coil induces a voltage $v(t)$ in the coil, driving a current $i(t)$ in the circuit. The combined force $f(t)$ on the moving charges in the magnetic field acts to oppose the relative motion, as described by Lenz's law. The mechanical work done against the opposing force is converted to heat in the resistance of the circuit and to stored energy in the magnetic field associated with the circuit inductance. Some key practical issues for electromagnetic energy harvesters are as follows: strong damping forces require rapid flux changes, which are difficult to achieve in small geometries 


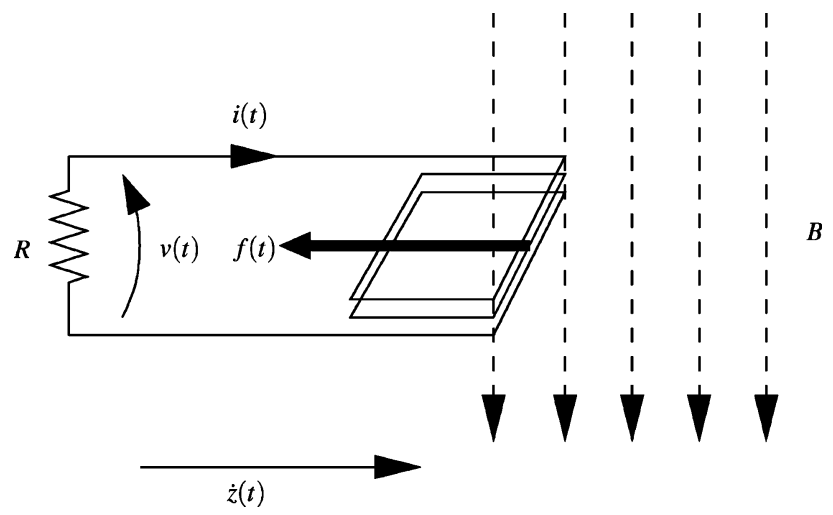

Fig. 4. Principle of operation of the electromagnetic transducer.

or at low frequency; the number of coil turns achievable in a MEMS or other microscale device will be limited, resulting in low output voltages; and integration of permanent magnets, and ferromagnetic materials for the flux path, is likely to be required.

In electrostatic generators, mechanical forces are employed to do work against the attraction of oppositely charged parts; in effect, such devices are mechanically variable capacitors whose plates are separated by the movement of the source. They have two fundamental modes of operation: switched and continuous [56]. In the switched type, the transducer and the circuitry is reconfigured, through the operation of switches, at different parts of the generation cycle. Switched transducers can further be split into two main types: fixed charge and fixed potential. The first is illustrated in Fig. 5(a). For a parallel plate structure with a variable separation and constant overlap (i.e., the horizontal component of $\dot{z}(t)$ is zero) and with a negligible fringing field, the field strength is proportional to the (constant) charge, and thus the energy density of the electric field is independent of plate separation. As the electrode separation increases [by doing mechanical work against the attractive force $f(t)$ ], additional potential energy is stored in the increased volume of electric field. If instead the plates are moved relative to each other laterally (i.e., the vertical component of $\dot{z}(t)$ is zero), mechanical work is done against the fringing field. There is an increase in stored electrical energy because the electric field strength increases with the reduction in plate overlap, and the energy density of the field (proportional to the square of field strength) increases faster than its volume decreases.

Constant voltage operation is illustrated in Fig. 5(b). If the plate separation is increased with a fixed overlap, the electric field strength falls, causing charge to be pushed off the plates into an external circuit as a current $i(t)$. If the plates are moved with constant separation and changing overlap, the field strength stays constant but current is again forced to flow into the source because the volume of the field decreases. In both cases, the mechanical work done is converted into additional electrical potential energy in the voltage source.

For both modes, since the charge equals the capacitance times the potential $(\mathrm{Q}=\mathrm{CV})$, and stored B energy is $1 / 2 \mathrm{CV}^{2}$, the electrostatic force is found to be half the voltage squared times the rate of change of capacitance, i.e.,

$$
F=\frac{1}{2} V^{2} d C / d z
$$

for motion in the $z$-direction. Thus a constant force is obtained for normal motion in the constant charge case

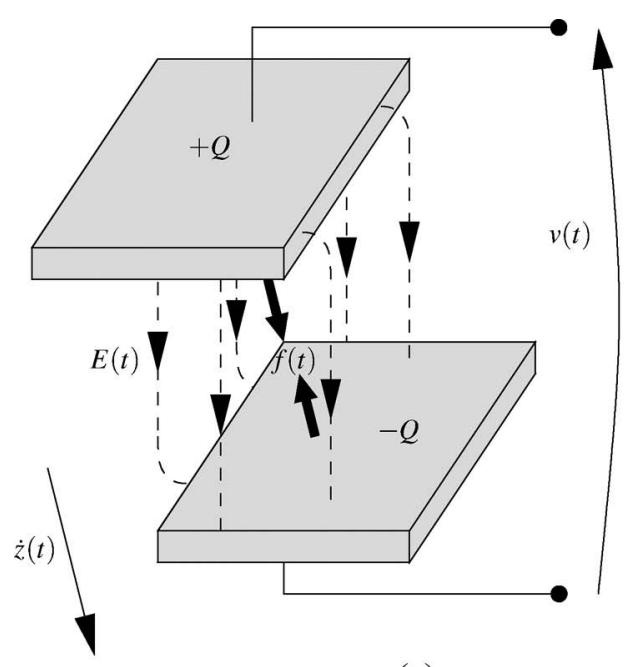

(a)

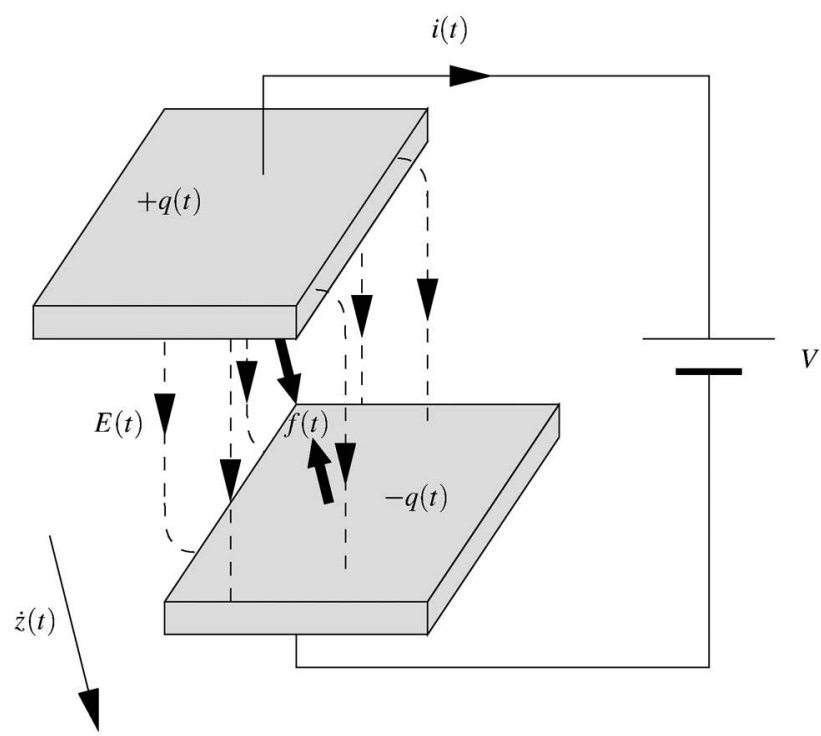

(b)

Fig. 5. Principle of operation of the electrostatic transducer: (a) constant charge and (b) constant voltage. 
and for lateral motion in the constant potential case. Because of practical constraints, such as nonzero conductance (for constant charge) and nonideal voltage sources (for constant voltage), real electrostatic transducers work somewhere between these two extremes, although in many cases very close to one or the other, and both types have been reported in the literature for implementations of energy harvesting microgenerators.

A practical restriction of electrostatic transducers is that they require a precharge (or priming) voltage in order to operate. This can be avoided by use of an electret, i.e., a permanent charge buried in a dielectric layer. On the other hand, since the damping force depends on the initial voltage, an active precharge system offers the possibility of dynamically optimizing the generator to the applied motion.

The piezoelectric effect is a phenomenon whereby a strain in a material produces an electric field in that material, and conversely an applied electric field produces a mechanical strain [57]. The former can be used to realize microgenerators. When an external force is applied, some of the mechanical work done is stored as elastic strain energy, and some in the electric field associated with the induced polarization of the material. If an external conduction path through a load is provided, a current that neutralizes the net charge results (Fig. 6). Piezoelectric materials with high electromechanical coupling coefficients are generally ceramics, with lead zirconate titanate being the most common. Such materials do not tolerate high strain levels, so some form of lever is required to combine them with devices of significant relative displacement. The most common geometry is to apply the piezoelectric as a thin layer on a cantilever beam from which the proof mass is suspended.

Although the three transduction methods above dominate the literature on energy harvesting, others are possible, such as the magnetostrictive effect [58].

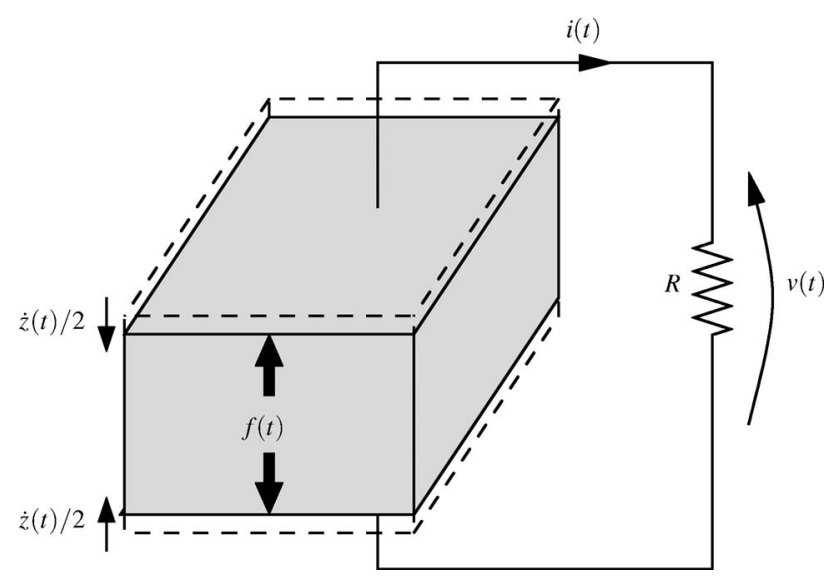

Fig. 6. Principle of operation of the piezoelectric transducer.

\section{Performance Limits}

Various estimates of the power available from motion energy harvesting, both empirical and analytical, have been reported. Niu et al. present a detailed study of biomechanical energy harvesting in [59]. They suggest that around $1 \mathrm{~W}$ is available from the heel strike of a shoe, and that a previous estimation by Starner [31] was very optimistic. The bending of the knee during walking is identified as one of the more promising opportunities to harvest energy from the body, because the leg muscles work against the motion of the leg for part of the gait cycle (while the leg is falling), during which time energy is turned into wasted heat. The authors estimate that up to $50 \mathrm{~W}$ could be harvested this way with little impact on the gait, although a large device would be required with wellseparated attachment points.

Von Büren et al. [60] consider the available power from a specific implementation of an inertial microgenerator powered by human walking motion. Acceleration data were collected from human male subjects walking on a treadmill and fed into a time-domain model of the generator in order to determine the available power. For a proof mass of $1 \mathrm{~g}$ and an available internal displacement of $5 \mathrm{~mm}$, power outputs as high as $200 \mu \mathrm{W}$ were calculated; this would appear to assume ideal harvester performance.

Analytic expressions for attainable power in the inertial device of Fig. 3 can be derived by assuming harmonic source motion, with amplitude $Y_{0}$ and frequency $\omega$, for which the maximum source acceleration $a_{\max }$ is $\omega^{2} Y_{0}$. The fundamental parameters determining a generator's output capability are its proof mass $m$, its resonant frequency (if any) $\omega_{n}$, and the maximum internal displacement $Z_{l}$. From basic considerations, we can derive a maximum power for any energy harvester driven by harmonic motion. The damping force by which the energy is extracted cannot exceed the inertial force on the proof mass, $m a_{\max }$; otherwise there will be no internal motion. By assuming that energy is extracted in both directions, and using the maximum motion range $2 Z_{l}$, a total energy per cycle can be derived of $4 Z_{l} m a_{\max }=4 Z_{l} m \omega^{2} Y_{0}$. To convert this to power is simply a matter of dividing by the excitation period $2 \pi / \omega$, giving

$$
P_{\max }=\frac{2}{\pi} Y_{0} Z_{l} \omega^{3} m
$$

If we make the restriction that the proof mass motion must be harmonic, as in a linear resonant device, then the maximum power is in fact somewhat less than this, since the acceleration is not $a_{\max }$ for the whole travel, and so the transduction force must be reduced accordingly. But (2) does provide, on the basis of fundamental considerations, an upper bound on the average power of an inertial energy harvester of any architecture, construction, transduction mechanism, or operating mode. It shows the linear 
dependence on mass and on travel range and the very strong dependence on frequency, indicating the serious challenge of achieving useful power levels in the lowfrequency environment of human motion.

Since mass is proportional to volume and maximum displacement to linear dimension, this maximum power scales as linear dimension to the fourth power, or as volume $^{4 / 3}$. Thus power density reduces as device size decreases, obviously an undesirable feature for miniaturization. In Fig. 7, the maximum power versus size is plotted for frequencies of 1 and $10 \mathrm{~Hz}$, as reasonable bounds for the fundamental component of human body motion. The values are computed from (2), assuming a cubic device with a proof mass of density $20 \mathrm{~g} / \mathrm{cc}$ taking up half its volume and the other half allowing its movement. It should be noted that, as shown in [61], power density varies significantly with device geometry as well as size. The source acceleration magnitude $\left(\omega^{2} Y_{0}\right)$ is fixed at $1 \mathrm{~g}\left(10 \mathrm{~m} / \mathrm{s}^{2}\right)$, representing quite vigorous motion (e.g., $25 \mathrm{~cm}$ displacement amplitude at $1 \mathrm{~Hz}$ ). Over this plot of harvester power, the approximate size and power consumption is plotted for each of four possible body-powered applications. It can be seen that a wristwatch of a few cubic centimeters and consuming a microwatt average power is easily within the achievable range, as is a sensor node of $0.5 \mathrm{cc}$ and $10 \mu \mathrm{W}$, but the cellphone and laptop both require harvesters as large as themselves, operating ideally and under constant excitation, to be entirely harvester powered. For comparison, a lithium-ion battery of density $1 \mathrm{~kJ} / \mathrm{cc}$ will provide an average power of $30 \mathrm{~mW} / \mathrm{cc}$ and $30 \mu \mathrm{W} / \mathrm{cc}$ for times between charging of $10 \mathrm{~h}$ and $1 \mathrm{y}$, respectively.

A detailed analytical framework for inertial energy harvesters is presented in [62]. This analysis allows different architectures to be compared quantitatively and derives the achievable power levels and their dependence on both source and device characteristics. Key practical constraints are also analyzed. The results of that study are summarized below. It was found that for idealized cases of the architectures considered, optimal output power can always be derived as a function of two dimensionless parameters $Z_{l} / Y_{0}$ and $\omega / \omega_{n}$ and can be normalized to a characteristic power $Y_{0}^{2} \omega^{3} m$.

One parametric and two resonant generator topologies were considered. Of the resonant types, one is damped by a force that is proportional to velocity, the velocity-damped resonant generator (VDRG), and the other is damped by a constant force, the Coulomb-damped resonant generator (CDRG). Of the nonresonant, nonlinear generators, only the Coulomb-force parametric-generator (CFPG) is discussed here, as the velocity-damped parametric generator was found to be ineffective. Variations of VDRGs and CDRGs have been extensively reported; broadly speaking, electromagnetic and piezoelectric devices correspond to VDRGs and electrostatic devices correspond to CDRGs. In this analysis, the resonant generators were considered to operate in modes in which the proof mass does not strike the end-stop limits, i.e.,

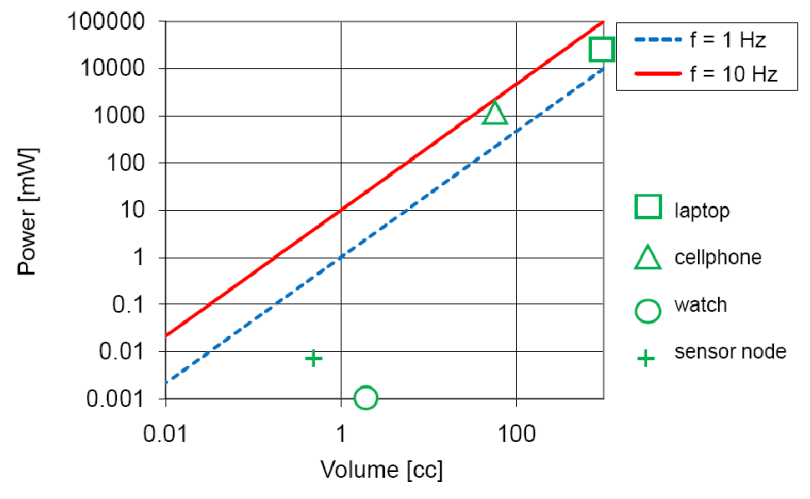

Fig. 7. Maximum power for motion driven harvesters as a function of size, for frequencies as shown, and size and power consumption of some possible applications.

$-Z_{l}<z(t)<+Z_{l}$, and thus the only forces that act on the mass are the inertial, spring, and damping forces.

Analysis of the output power can be done by integrating the product of the damping force and the incremental displacement and averaging this over a cycle. Then the optimum power can be found by choosing the damping coefficient to maximize this value. However, if resonant motion is assumed without regard to travel limits, a derivation is obtained that indicates infinite power at resonance, although a corresponding infinite internal displacement is implied. A realistic assessment requires that the damping force be reduced only to the limit imposed by the maximum travel range. Thus, the achievable power of an ideal VDRG takes two forms: first, if the damping can be optimized without the displacement constraint being breached

$$
P_{\max }=\frac{\omega_{c}^{2} Y_{0}^{2} \omega^{3} m}{\sqrt{1-2 \omega_{c}^{2}+\omega_{c}^{4}}}
$$

and secondly, if the damping is constrained by this displacement limit

$$
P_{\max ^{c z}}=Y_{0}^{2} \omega^{3} m \frac{1}{2 \omega_{c}^{2}}\left(\frac{Z_{l}}{Y_{0}}\right)^{2} \sqrt{\omega_{c}^{4}\left(\frac{Y_{0}}{Z_{l}}\right)^{2}-\left(1-\omega_{c}^{2}\right)^{2}} .
$$

In each case, $\omega_{c}$ is the normalized frequency $\omega / \omega_{n}$. It can easily be shown that for harmonic operation at resonance $\left(\omega_{c}=1\right),(4)$ reduces to

$$
P_{\text {res }}=\frac{1}{2} Y_{0} Z_{l} \omega^{3} m
$$

This is just a factor $\pi / 4$ less than the more general limit given by (2). 
The Coulomb damped devices do not form linear systems because the damping force is discontinuous at the boundaries (where the direction changes), and so analytical solutions are not as straightforward to obtain. Nevertheless, closed-form solutions to the equations of motion for the CDRG do exist, from which the optimal damping coefficients, and the achievable power levels, can be derived. Just as for the VDRG, the maximum power depends on whether or not the optimal damping is limited by the internal displacement constraint. If not

$$
P_{\max }=\frac{\sqrt{2}}{\pi} Y_{0}^{2} \omega^{3} m \frac{\omega_{c}^{3}}{\left|\left(1-\omega_{c}^{2}\right) U\right|}\left[\frac{1}{\left(1-\omega_{c}^{2}\right)^{2}}-\frac{U}{\left(1-\omega_{c}^{2}\right)}\right]^{\frac{1}{2}}
$$

although for $\omega_{c}<0.72$, this is not valid because the calculated optimal force results in sticking in the motion. For displacement constrained operation

$$
P_{\max ^{c z}}=\frac{2 \omega_{c} Y_{0}^{2} \omega^{3} m}{\pi|U|}\left(\frac{Z_{l}}{Y_{0}}\right) \sqrt{\frac{1}{\left(1-\omega_{c}^{2}\right)^{2}}-\frac{1}{\omega_{c}^{4}}\left(\frac{Z_{l}}{Y_{0}}\right)^{2}} .
$$

In both cases the function $U$ is defined as

$$
U=\frac{\sin \left(\frac{\pi}{\omega_{c}}\right)}{\left[1+\cos \left(\frac{\pi}{\omega_{c}}\right)\right]} .
$$

It can easily be shown that at resonance, (7) reduces to (5), i.e., the optimum power of the CDRG and VDRG are the same if operated at resonance.

The analysis of the CFPG is essentially the same as that used to derive (2); the Coulomb (electrostatic) force is constant for the whole travel distance, and so the energy per transit is just the applied force times the travel range. However, a correction is needed to (2) because the force applied, in the case of harmonic source motion, cannot be equal to $a_{\max }$ since this acceleration is reached only instantaneously at the extremes of the frame displacement. Thus the damping force must be reduced to $\beta a_{\max }$, where $\beta$ is a dimensionless coefficient less than one, giving

$$
P_{\max }=\frac{2 \beta}{\pi} Y_{0} Z_{0} \omega^{3} m
$$

In this general formulation, the displacement limit of the device $Z_{l}$ has been replaced by the actual internal motion amplitude $Z_{0}$. Thus, determination of the output power requires not only the optimal value of $\beta$ but also the corresponding internal amplitude $Z_{0}$ to be determined. For large source displacement amplitudes, however, it can be shown that the optimal $\beta$ value is that value that just allows the full travel range to be traversed, so that $Z_{0}=Z_{l}$. Specifically, this proves to be the case for $Z_{l}<0.566 Y_{0}$, i.e., the source motion amplitude is more than about double the internal displacement limit. This is likely to be the case for wearable or implanted devices excited by body or limb motion. It may not be the case for implanted devices driven by cardiac motion, and is unlikely to be for many vibration-driven applications.

Comparison of the achievable power levels of the three architectures can be used to determine which is the most effective for a given operating regime. Fig. 8 shows the result, indicating the operating regions where each architecture is superior and what the maximum power level is, normalized to $Y_{0}^{2} \omega^{3} m$.

Several general conclusions can be drawn from Fig. 8. For large devices or low source amplitudes $\left(Z_{l} / Y_{0}>0.1\right)$, the resonant devices are superior, except where the frequency of operation is less than half the resonant frequency, in which case the parametric generator is preferred. The enhancement obtained by resonant operation is proportional to the ratio $\left(Y_{0} / Z_{l}\right)$, which corresponds to the mechanical $\mathrm{Q}$ (quality factor) of the resonance. The CFPG is superior for all cases where the device size is well below the source motion amplitude. As mentioned above, this is likely to be the case for many BSN applications. Furthermore, the CFPG, being nonresonant, can operate effectively over a wide range of source frequencies and waveforms without the need for dynamic tuning.

In fact, the spectral characteristics of motion sources are a critical factor in the feasibility of energy harvesting. If a device with fixed resonant frequency is driven by a harmonic source of varying frequency, then the output

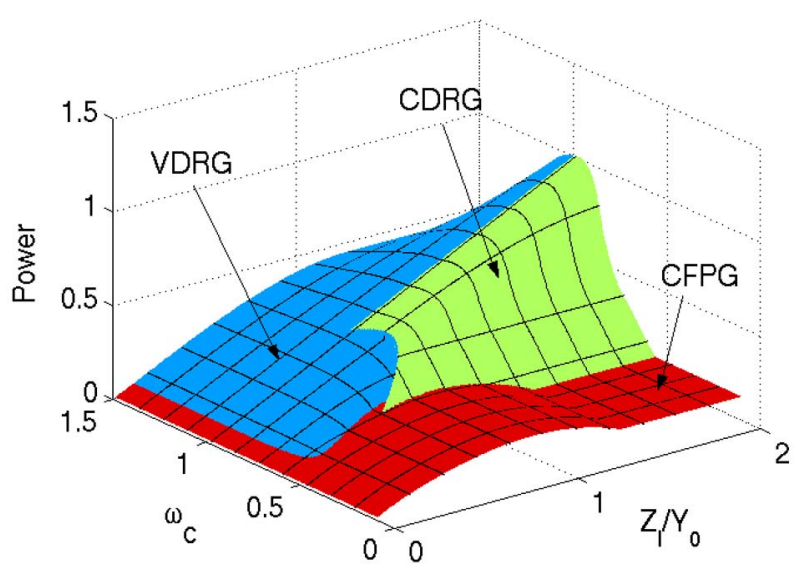

Fig. 8. Maximum normalized power for inertial energy harvesters versus operating parameters, showing the architecture with the highest power in each operating region (from [62]). 
power will vary with $\omega_{c}$, as indicated by the equations above, but only if the damping factor can be dynamically optimized. If this is also fixed, the loss of power as operation moves away from resonance will be even greater. If the excitation is nonharmonic in nature, then optimal power extraction is likely to require a damping force and corresponding mechanical $\mathrm{Q}$ adapted to the bandwidth of the motion. Clearly body motion is of complex and varying spectral form, and for that reason analysis of the output of inertial energy harvesters with realistic body-motion excitation has been carried out [63]. Motion waveforms were captured using accelerometers for three orientation axes, at each of a number of body locations. The power output of the various harvester architectures, for a range of sizes, was simulated and compared using these waveforms. The results are shown in Fig. 9. As anticipated, the CFPG devices are superior for small sizes, particularly for lower body locations where the displacements are greater. It should be noted that these results assume that the optimum damping factor can be achieved in every case; in fact this may not be the case, and the limits on damping strength depend on the transduction method chosen. Analysis of resonant inertial generators driven by random waveforms has been reported by Halvorsen [64], where it is shown that the optimal load for maximum power extraction is different from that for harmonic excitation.

For applications, such as body-mounted sensors, where the source amplitude exceeds the device size, resonant enhancement of the internal motion amplitude is not required, and so broadband operation is compatible with maximizing output power. The key practical difficulty in this case is achieving a strong enough damping force in the transduction mechanism. For higher frequency motion sources such as machine motion, however, resonant operation is generally desirable, as discussed in more detail below. However, this is inherently associated with narrow

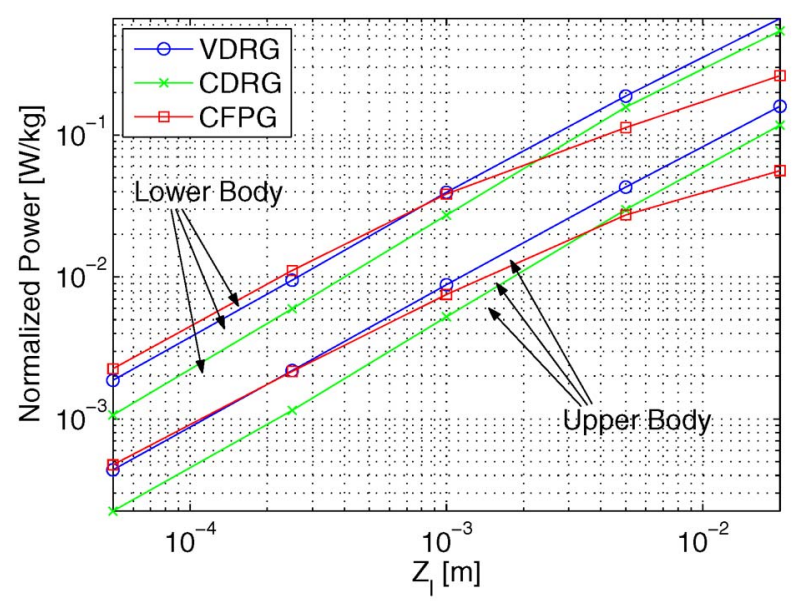

Fig. 9. Performance of the three microgenerator architectures as a function of size, when operated on the human body (from [63]). bandwidth, which creates a problem when the source frequency is variable or not precisely known in advance. Increasing the transduction damping factor, where possible, will increase the response bandwidth, but at a penalty in output at the center frequency. Wider frequency response can also be obtained using higher order resonators, and in [65] designs of this type, using multiple masses and springs, are proposed and analyzed. Flat frequency response over an extended spectral range is obtained, but again at the cost of reduced response compared to a high $\mathrm{Q}$ device at resonance. For simple damped resonators, the bandwidth and peak response are inversely proportional to a good approximation, so that doubling the frequency range (for example) halves the peak output power. For the coupled oscillator devices in [65], a similar tradeoff is shown, the key advantage being that a much flatter response can be obtained within the operating bandwidth.

A better solution to varying source frequency, for higher $\mathrm{Q}$ devices, would be active tuning of the resonant frequency. In [66], Roundy and Zhang look at a design methodology for online tuning of resonant inertial microgenerators by varying the spring constant or the value of the proof mass, with the former being clearly the more feasible. Actuators to perform the tuning are placed into two categories, active and passive, according to whether frequency adaptation is continuous or intermittent respectively. A passive actuator might alter the length, and thus the spring constant, of a cantilever using a moveable clamp. An active actuator might operate by creating a variable spring-like force proportional to displacement, e.g., electrostatically. In [67], a passively tunable device is reported in which the resonant frequency of a piezoelectric cantilever is shifted by the application of magnetic forces, and tuning achieved by adjusting the relative positions of the magnets. The untuned half-power bandwidth is $2 \mathrm{~Hz}$, and a tuning range of $10 \mathrm{~Hz}$ is demonstrated.

Most reported analysis of inertial energy harvesters is for devices with linear internal motion, excited by linear source motion. However, although most reported devices are of this type, rotational internal motion is also possible, with wristwatch generators the notable examples. Analysis of the possible operating modes and power limits of rotating mass generators is presented in [68], and power densities are found to be similar to the linear cases for realistic excitation scenarios. Recently, a rotating harvester has been reported that can be connected to a single point on a source rotating at constant speed [69]. In this case, since a counterforce to the input cannot be provided by proof mass inertia, it is instead provided by gravitational torque, using an offset mass.

\section{Comparison of Transduction Methods}

One important limitation to the analysis above is that the damping is assumed to be entirely due to the energyharvesting transducer, whereas in reality there will also be parasitic damping, resulting, for example, from air 


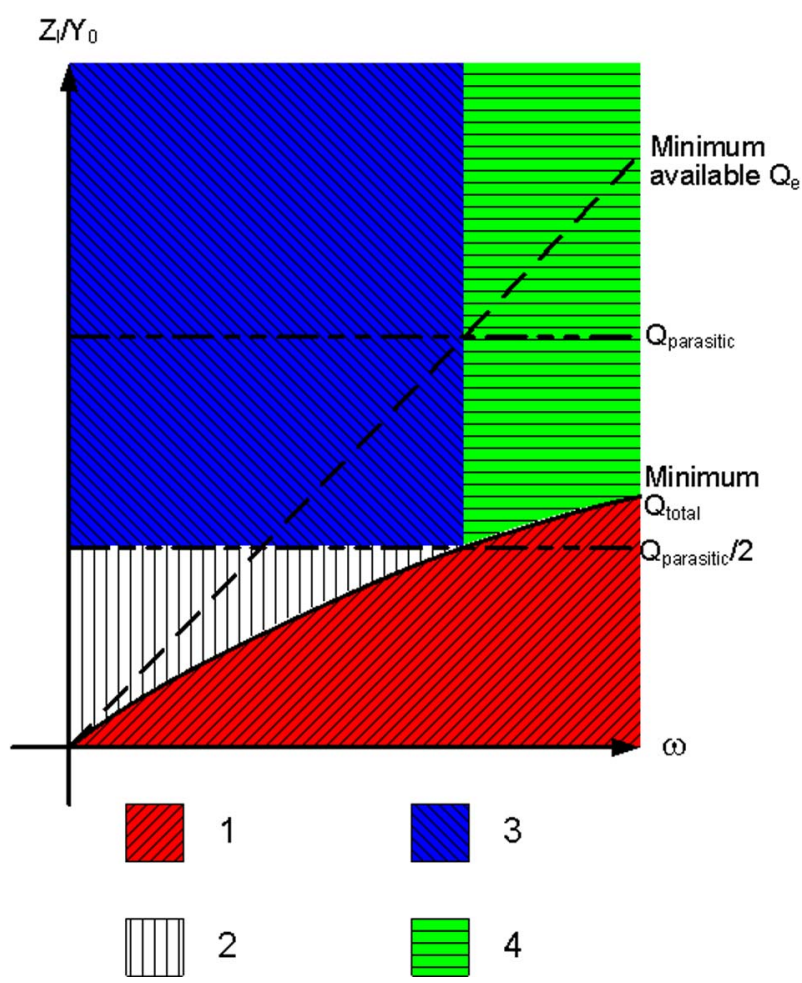

Fig. 10. Damping optimization strategies versus operating regions (from [70]).

resistance. This will be a particularly important effect for applications where the source motion is less than the harvester internal displacement, as is likely with highfrequency sources such as machine vibration. For resonant devices, this effect can be introduced by way of a parasitic quality factor $Q_{p}$, which is the $\mathrm{Q}$ that would be obtained if only the parasitic damping was present. If the $\mathrm{Q}$ resulting from the electrical (transducer) damping is $Q_{e}$, then the combined $Q$ will be given by $1 / Q_{t}=1 / Q_{e}+1 / Q_{p}$. If $Z_{l} / Y_{0}$ and $\omega$ are then used as general operating parameters, limits of operation can be plotted for electromagnetic and piezoelectric devices. By adding the $Q_{p}$ and $Q_{t}$ of the device, regions of operation can then be indicated as a function of operating point [70] and optimal strategies can be identified for each of these.

The regions are illustrated in Fig. 10 schematically, for devices with parasitic damping present, operated at resonance. The parasitic $\mathrm{Q}$ is assumed to be constant with frequency for simplicity, but any actual frequency dependence could easily be substituted. The operating regions are as follows.

1) Harmonic motion is not possible. The maximum combined damping is less than required for oscillation within $Z_{l}$ and so the mass will strike the end-stops. Here the electrical damping should be set to the maximum achievable. Most bodymounted devices will be in this regime.
2) In this region, for optimal operation, the electrical damping should be set to give $Z_{0}=Z_{l}$. Electrical damping will be greater than parasitic damping, and so this generator can achieve the maximum power for the level of parasitic damping present.

3) Here the electrical damping should be set to equal the parasitic mechanical damping, i.e., $Q_{e}=Q_{p}$. This will give $Z_{0} / Y_{0}=Q_{p} / 2$. Many machine vibration powered devices will be in this regime.

4) Here the electrical damping should be set to the maximum that can be achieved, but it will still be less than the parasitic damping, i.e., $Q_{e}>Q_{p}$. The generator can operate within the displacement constraint, but a different transducer could in principle extract more power.

Figs. 11 and 12 show two specific examples of the minimum Q-factor achievable from electromagnetic and piezoelectric generators, as reported in [70]. In each case, the device is taken as cubic, having length $\mathrm{L}$ and a mass of relative density $8.9(\mathrm{Ni})$ occupying half the volume. The electromagnetic device is assumed to have a flux density of $1 \mathrm{~T}$ and a copper coil occupying $2 \%$ of the device volume, and an active coil length L/2. For the piezoelectric device, $\epsilon_{r}$ is taken as 1000, area $L^{2}$, thickness $L / 10$, and $e_{33}=0.15 \mathrm{C} / \mathrm{m}^{2}$. A leverage factor of 500 was chosen. Because $Q_{\min }$ for electromagnetic and piezoelectric devices scales as $\omega$ and $\omega^{2}$, respectively, there will always be a frequency above which electromagnetic devices can achieve stronger damping (lower Q). As can be seen in Figs. 11 and 12, the crossover frequency increases as device size decreases. It can also be observed that the increasing minimum $\mathrm{Q}$ with frequency (for both transducer types) could explain the decreasing performance trend seen in Fig. 28.

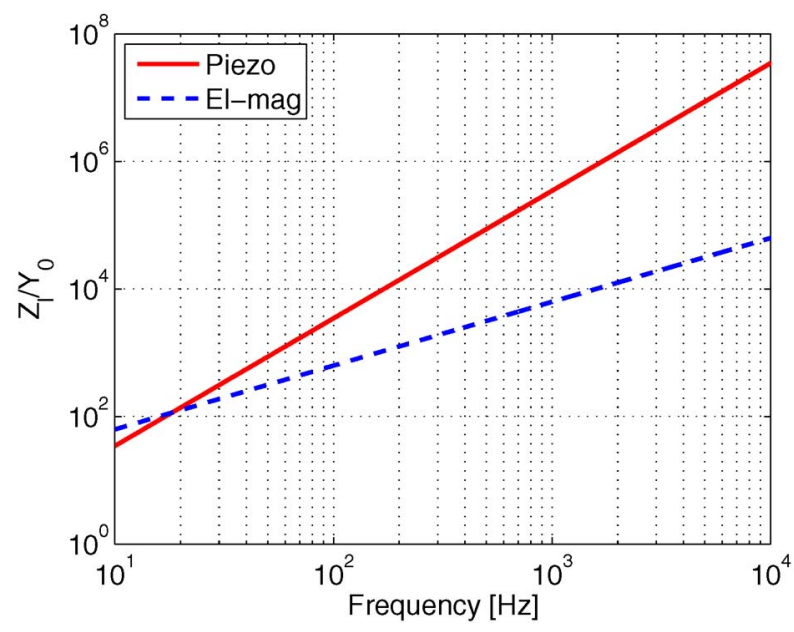

Fig. 11. Comparison of minimum $Q$ factors with electromagnetic and piezoelectric cube devices of volume 1 cc (from [70]). 


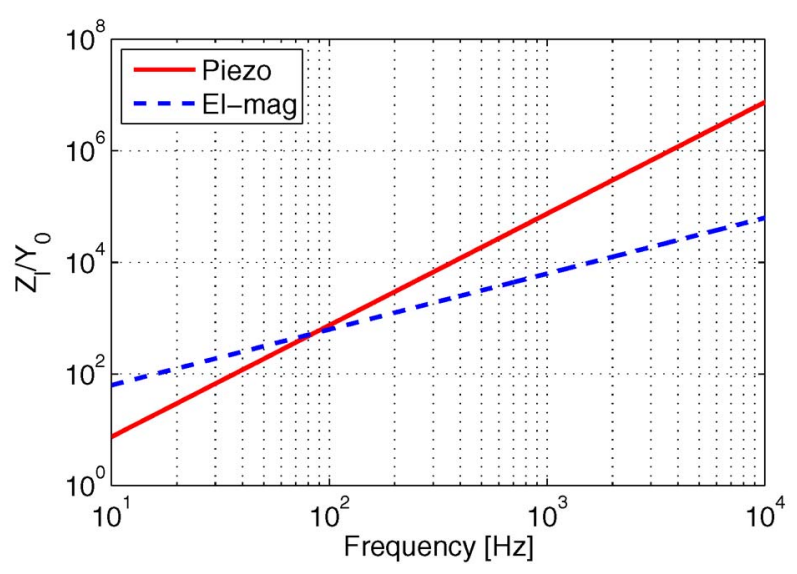

Fig. 12. Comparison of minimum $Q$ factors with electromagnetic and piezoelectric cube devices of volume 0.1 cc (from [70]).

\section{REPORTED MOTION-ENERGY HARVESTERS}

A large number of research groups are currently active in the field of motion-energy harvesting, and a wide range of devices and applications have been reported. General reviews of this work have also been published, such as [71]. Here we summarize some of the key developments and trends, with examples for each of the main device types.

\section{A. Direct Force Generators}

Significantly less work has been reported on directforce generators than on the inertial type, possibly because of the restricted application scenarios for the former, particularly for miniature devices. The first reported work appears in the patent literature. In [72], Enger proposes a health-monitoring system powered by a piezoelectric bimorph, which could be driven by the movement of adjacent body tissue. The device described contains an RF transmitter, which would operate intermittently, at a rate depending upon the rate of power generation.

The first reported work on direct-force microgenerators in the research literature is by Umeda et al. [73]. They note that portable electronic equipment is often subjected to mechanical shock during transportation and investigate generation from such shock using a piezoelecric beam, clamped at both ends, when a steel ball is dropped onto it.

González et al. address the problem of powering portable electronics in [74] and [75]. They consider common portable electronic items such as personal digital assistants and $\mathrm{mp} 3$ players, and suggest that an average of $18-110 \mathrm{~mW}$ is required to run the devices that might be carried around by a typical user. The authors assume that as semiconductor devices shrink, the power requirements to perform a given function scale as the linear dimension cubed because of a linear decrease of size and of supply voltage. It should be noted, however, that reducing the supply voltage of a circuit means that the devices require reduced threshold voltages, and thus static power dissipation can increase, and that some functions (such as displays) have limited capacity for size reduction. The authors conclude that around $1.2 \mathrm{~W}$ could be harvested from human walking using piezoelectric materials (although the particular configuration is not described), and that $78 \mathrm{~mW}$ could be harvested from the expansion of the chest from breathing.

Paradiso et al. of the MIT Media lab have investigated power-harvesting from running shoes [76]-[78] as a method of generating power for wearable electronics. The authors describe three types of generators: a piezoelectric bender placed in the sole, which flexes during the human gait; a unimorph attached to a curved steel plate, which flexes under the pressure of a heel strike, as shown in Fig. 13; and a rotating electromagnetic generator in the heel, operated from a lever that is pressed as the heel strikes the ground. The piezoelectric sole and heel generators produce around 2 and $8 \mathrm{~mW}$, respectively, and the electromagnetic generator is capable of $250 \mathrm{~mW}$. The harvested power is used to supply an RFID tag transmitting an identification string every few steps. Although the electromagnetic generator was capable of harvesting one to two orders of magnitude more power than the piezoelectric ones, it was reported to have a noticeable effect on the user's gait. The authors suggest that the piezoelectric solutions are neater, and with the everreducing power consumption of wearable devices, their power output will be sufficient.

In [79], Kim et al. discuss the use of a piezoelectric cymbal transducer to generate electricity from the vibration of a car engine. A cymbal-shaped device was chosen because the authors state that this structure is efficient at transferring stress through the material. The transducer would be placed between the engine and engine mounting, so that force is directly applied to it. The available power is calculated from the effective capacitance and open circuit voltage of the piezoelectric element. A fabricated device was tested on a shaker, and the efficiency of the system was

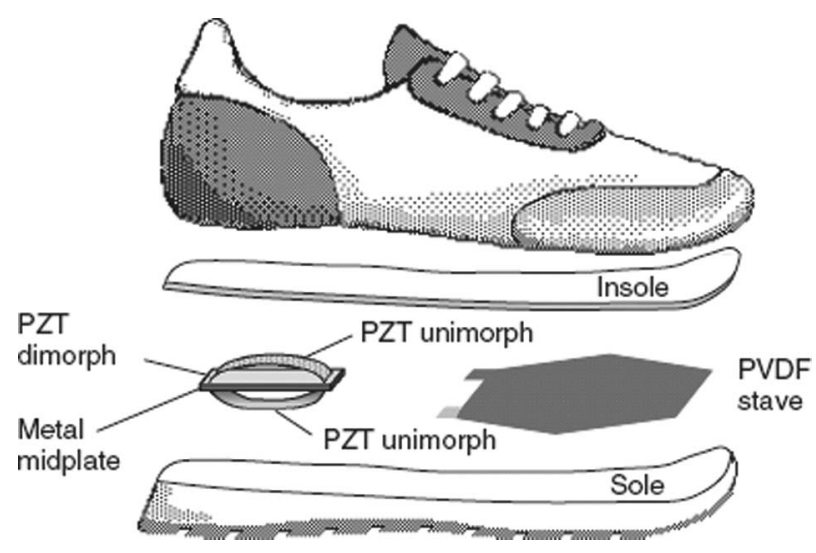

Fig. 13. Energy-harvesting shoe (from [77]). 
calculated to be $7.5 \%$, although the accuracy of the method used for calculating the mechanical energy input to the system is uncertain. The device was then connected to a full wave rectifier, smoothing capacitor, and buck converter, giving a maximum processed output of about $30 \mathrm{~mW}$. The target application is charging of the car's battery, for which the device size and power levels will need to be much higher.

Lu et al. describe the modelling and analysis of a piezoelectric generator in [80] for remote system monitoring. They suggest that using the $d_{31}$ piezoelectric coefficient (where the field is normal to the applied force) is more suitable to MEMS applications than the $d_{33}$ coefficient (where the force and field are parallel) because the former allows the piezoelectric material to be strained on a bending cantilever. This mode of operation has indeed been the most widely adopted. The authors derive a closedform expression modelling a cantilever with known acceleration at the free end of the beam when driving a resistive load. The solution is valid for a direct-force application generator rather than an inertial generator. The authors show that there is an optimal load resistance that will obtain the maximum electrical power.

Clark and Ramsay consider force-driven piezoelectric generators [81] for medical applications. The input energy for the generator is intended to be in the form of fluctuating pressure in a blood vessel. The authors study a square sheet of piezoelectric material held in a rigid frame, with pressure applied normal to the sheet surface. They find that the generated power increases as the sheet thickness is decreased but, for the given operating frequency of $1 \mathrm{~Hz}$, a $1 \mathrm{~cm}^{2}$ sheet of piezoelectric material can only generate around $1 \mu \mathrm{W}$. They suggest that the supply could be used to power load electronics at a low duty cycle.

The possibility of harvesting energy from bending of the knee, as discussed in Section III-C, has been realized by Donelan et al. [82]. Their device extends over substantial portions of the upper and lower leg, so that large torques can be produced, and output powers up to $7 \mathrm{~W}$ for normal walking motion are obtained. The metabolic cost is reduced by the generative braking action of the device, i.e., the transduction is actually assisting the leg motion on the decelerating portion of the stride.

\section{B. Electromagnetic Inertial Generators}

The first examples of inertial generators using electromagnetic transducers are to be found in the patent literature. While mechanical self-winding watches were successfully made by Perrelet around 1770 [83], the first description of an electrically operated self-winding watch, and indeed of a small inertial energy harvester, is a patent filed in 1989 by Hayakawa of Seiko Epson Corporation [84]. This describes the ideas behind the Seiko Kinetic watch, which is now a commercial product. An exploded view of the Kinetic generator is shown in Fig. 14. An asymmetric proof mass, freely rotating about a point some distance from its center of mass, is attached to a permanent magnet electrical generator, through high ratio gears. A more generic patent on inertial generators, from Tiemann in 1996 [85], proposes the use of relative movement between magnets and coils in a mass-spring system to generate electrical energy from linear vibrational motion.

In the research literature, the first description of an inertial microgenerator was of an electromagnetic type driven by reciprocating vibration, presented by Williams and Yates in 1995 [86]. Significant contributions of this work are the application of the model of Fig. 3 to inertial microgenerators, and the development of an equation for power generation for linear inertial generators, based on material presented by Thomson in [87]. Some basic insights are given into the choice of generator design parameters, e.g., that operating the generator at its resonant frequency, and reducing the damping so that the mass moves to the limit of its travel, are both beneficial to power generation. It is also stated that both the mass and internal travel range should be maximized. In fact, since (2) shows that maximum power is proportional to both mass and internal travel range, the optimal tradeoff between mass and displacement is for the swept volume of the proof mass to be twice its physical volume, since this maximizes the product of travel range and mass dimension in the direction of travel (by making the two equal). Power levels from 1 to $100 \mu \mathrm{W}$ are calculated for generators with a $15 \mathrm{mg}$ mass operating between $70 \mathrm{~Hz}$ and $3.3 \mathrm{kHz}$. These papers assume a real load, neglecting the inductance of the coil; this is a valid approximation providing the reactance of the coil is negligible at the operating frequency.

In [88], Shearwood and Yates report the first measured results from a microengineered inertial generator (Fig. 15). The device is similar in structure to a microphone and was fabricated by patterning a planar coil on the underside of a wafer, etching a cavity on the top, and attaching a rare-earth magnet of mass $2.4 \mathrm{mg}$ on a flexible membrane above the cavity. An average output of $0.33 \mu \mathrm{W}$ was obtained from a $4.4 \mathrm{kHz}$ input vibration. The measured power agrees with the model at low input amplitudes, but for high amplitude inputs, spring stiffening changes the resonant frequency and thus the output is less

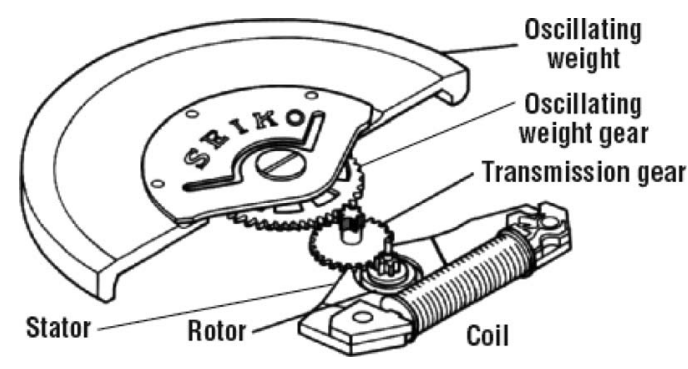

Fig. 14. Exploded view of Seiko Kinetic watch (courtesy of Seiko Instruments Inc.). 

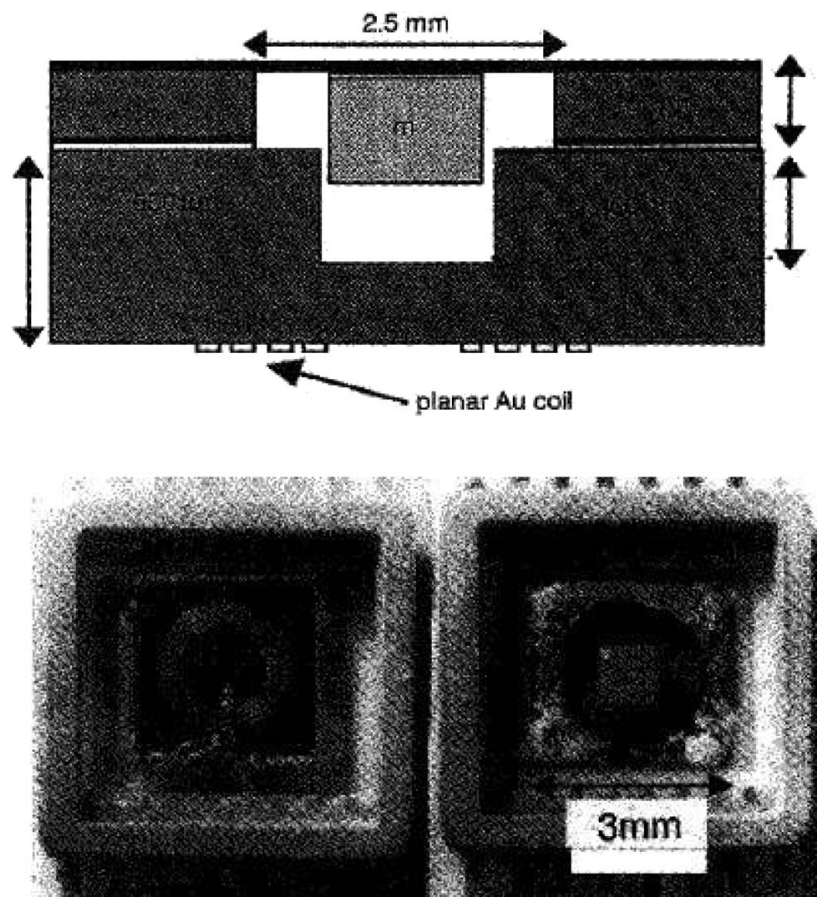

Fig. 15. Electromagnetic generator (from [88]).

than predicted, highlighting the potential disadvantage of narrow bandwidth associated with using resonant structures in these systems.

In [89], for the first time, an equivalent electrical circuit of the mass-spring damper system is used to calculate an equation for the power output of linear inertial generators. It is shown that, for maximum power generation, the electrical damping should be impedance matched to the equivalent circuit impedance of any parasitic damping, such as air damping. An advantage of mapping the mechanics of the system into the electrical domain is that it is then relatively easy to calculate generator performance when loaded with an arbitrary electrical circuit. Consequently, in this paper, the self-inductance of the coil is included for the first time.

Digital integrated circuits and systems reseachers at MIT, led by Chandrakasan, have investigated energyharvesting electromagnetic microgenerators for low-power signal-processing applications [90]. The aim of this research was to realize a self-powered digital signalprocessing (DSP) system having a generator and backup voltage source, a voltage regulator, and a low-power DSP. The authors built a generator from discrete components, with fixed magnet and moving coil, having a proof mass of $0.5 \mathrm{~g}$ and a resonant frequency of $94 \mathrm{~Hz}$. They note that the output voltage $(180 \mathrm{mV})$ induced is too low to be rectified by a diode, and conclude that their system requires a transformer, or more coil turns. For the first time, human walking motion is considered and a simple model given. Simulations show that around $400 \mu \mathrm{W}$ can be generated from this motion, although since parasitic damping effects are not taken into account the figure presented is an upper bound. The authors also designed and fabricated a synchronous $\mathrm{dc}-\mathrm{dc}$ converter for the system, using integrated transistors and discrete passive components.

A group of researchers from the Chinese University of Hong Kong have reported an electromagnetic generator with a laser micromachined spring [91]. This device also suffers from insufficient output voltage, so a standard voltage quadrupler circuit is used to obtain just over $2 \mathrm{~V}$. The $1 \mathrm{~cm}^{3}$ generator is shown to produce $40 \mu \mathrm{W}$ of power after rectification, when driven from an input vibration of between 60 and $120 \mathrm{~Hz}$, and is used to successfully drive a commercial infrared transmitter at a duty cycle of $1 \%$. The same generator is also presented in [92], which describes the integration of a microcontroller, temperature sensor, and FM transmitter into the self-powered system. The transmission of temperature data over a distance of $25 \mathrm{~m}$ is demonstrated.

In [93], El-Hami et al. took a more fundamental approach to electromagnetic inertial generator design than previous authors. They describe an improved device that uses four magnetic poles to give two flux paths flowing in opposite directions (Fig. 16), thus doubling the rate of change of linked flux compared to a two-pole design. In [94], the same research group reports a condition monitoring system powered from their four-pole electromagnetic harvester, tuned to $102 \mathrm{~Hz}$ and generating $2.5 \mathrm{~mW}$ for a source displacement amplitude of $0.4 \mathrm{~mm}$. A charge pump voltage doubler circuit, and its advantages in size and efficiency over a transformer and rectifier solution, are described. This selfpowered system measures acceleration and uses an infrared communications link to transmit the data.

In a European collaborative project called VIBES, a millimeter-scale cantilever beam device was developed [95], also using the four-pole configuration (Fig. 17). The intended motion source is an air compressor producing large vibration amplitudes at 50 and $60 \mathrm{~Hz}$. The device volume is $150 \mathrm{~mm}^{3}$ and the measured output was $17.8 \mu \mathrm{W}$ at $89 \mathrm{mV}$, for a frequency of $60 \mathrm{~Hz}$ and input acceleration $0.6 \mathrm{~m} / \mathrm{s}^{2}$.

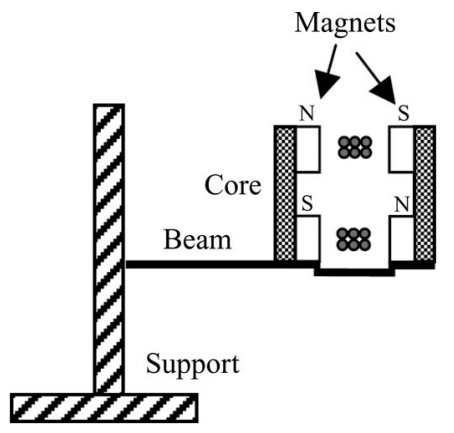

Fig. 16. Four-pole electromagnetic generator (from [93]). 


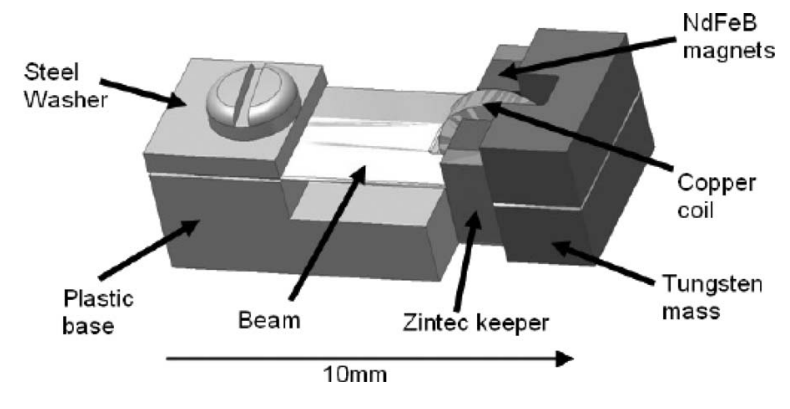

Fig. 17. Cantilever EM generator (from [95]).

In [96], a method of optimization of electromagnetic generators is simulated and demonstrated experimentally. The authors considered a cantilever beam structure, and two centimeter-scale generators were developed with varying parasitic damping. The condition for maximum power transfer for devices with strong parasitic damping is shown to be when the coil resistance is equal to the load resistance.

Inertial generators using electromagnetic transduction have also been developed at larger size scales. Rome et al. [97] report backpack devices containing spring-mounted proof masses of 20-38 kg, with the internal motion damped by a conventional dc generator coupled to the proof mass via a gear train. Output powers up to $7.4 \mathrm{~W}$ are obtained. As for the knee-bending device of [82], the metabolic cost of this power extraction is less than would be expected based on muscle efficiency, and this is attributed to adaptation of the gait to maximize efficiency.

A more comprehensive review of miniature electromagnetic generators is presented in [98], which covers conventional as well as inertial devices, presents scaling laws, and discusses the significance of recent developments in permanent magnet technology.

\section{Electrostatic Inertial Generators}

Chandrakasan's group at MIT has investigated MEMSbased electrostatic harvesters, and in [99] and [100] they report the first electrostatic microgenerator work in the literature. These papers consider both the generator and the associated control circuitry. They describe in detail a comparison between constant charge and constant voltage operation cycles, showing through the use of QV cycle plots that constant voltage operation is superior to constant charge operation for maximizing power generation (although this conclusion is dependent on specific constraints on maximum operating voltage and capacitance ratios in the devices considered). The authors achieve constant voltage operation by attaching a large fixed capacitor in parallel with the variable capacitor. A power processing circuit is described, and optimizations are performed on the dimensions of the metal-oxide-semiconductor field-effect transistors (MOSFETs) and the inductor size to implement the chosen QV cycle. Simulations of the device show that this generator should produce $8.6 \mu \mathrm{W}$, with approximately $5.6 \mu \mathrm{W}$ being available for driving a load and the rest being used by the control scheme.

The proposed design of the variable capacitor has evolved throughout the work presented by this MIT group. In [101], the capacitor is a MEMS comb drive with 7- $\mu \mathrm{m}$ wide trenches, $500 \mu \mathrm{m}$ deep, giving an aspect ratio of around 70 (Fig. 18). The device would operate in constantgap mode with sliding combs, which is preferred to a variable-gap parallel-plate capacitor because of the linear change in capacitance with displacement for the former, making control timing less critical than with the nonlinear capacitance variation of the latter. However, attention later moved to a parallel plate device with variable gap because of fabrication difficulties for the comb drive. Further analysis of the QV cycles is also given in [102], where efforts are now concentrated on a constant charge cycle and the power electronics for implementing that cycle, since the circuits are deemed to be simpler to implement for this case. No test results are presented for the MEMS fabricated device. A discussion of the power electronics in this paper is given in Section VI.

A major research effort on inertial microgenerators has been undertaken by Roundy et al. at the University of California at Berkeley. In [103], the authors describe the design, optimization, and fabrication of a comb-drive inertial generator similar in concept to the initial work by Chandrakasan et al. In [2], Roundy describes three different topologies for electrostatic generators: in-plane

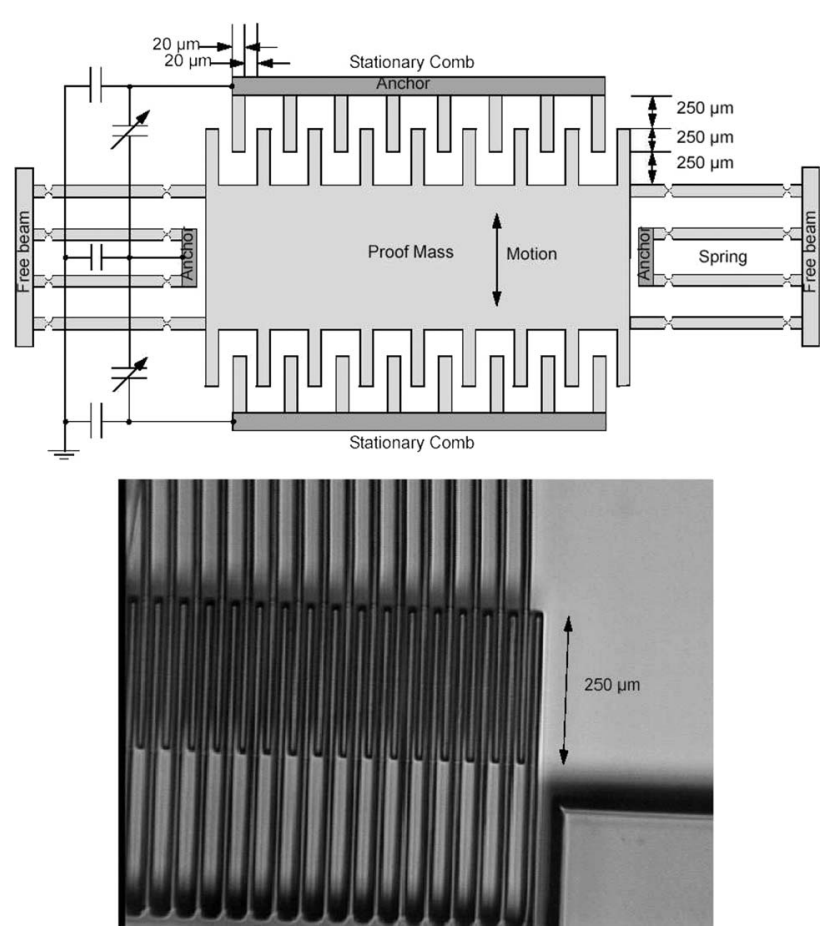

Fig. 18. Electrostatic generator (from [99] and [100]). 
overlap, in-plane gap closing, and out-of-plane gap closing. Expressions for parasitic air damping are given, and it is stated that when operating in air, the out-of-plane gapclosing generator will suffer particularly badly from fluid damping. This conclusion is based on the assumption that a very small gap must be achieved to produce high power density. Although this is not a fundamental requirement, it is likely to be a practical one, both to overcome parasitic capacitances and to avoid excessive priming voltages. Roundy notes that the out-of-plane device is significantly harder to fabricate using standard MEMS technology than the in-plane types; in MEMS devices, movement is generally designed to occur in the plane of the wafer. The tradeoff between reduced travel and the number of fingers for the in-plane gap-closing generator is comprehensively explored and an optimal number of fingers found.

Simulations in Simulink are used by Roundy et al. to investigate the effect of design parameters such as pressure and dielectric thickness. They note that there are stability pull-in problems associated with electrostatic comb structures, and they anticipate that the pull-in distance will set the minimum dielectric gap. The authors conclude that the in-plane gap closing design can achieve the highest power density because it does not suffer from electrostatic pull-in or excessive parasitic damping. It is estimated that such a device would generate around $100 \mu \mathrm{W} / \mathrm{cm}^{3}$ from a vibration source of $2.25 \mathrm{~m} / \mathrm{s}^{2}$ at $120 \mathrm{~Hz}$. A scanning electron microscope picture of the device is shown in Fig. 19.

In [2], initial test results for a harvester are presented. Diode-connected unpackaged junction field-effect transistors were attached to the MEMS die using fluidic selfassembly. Using an integrated thermal actuator, the combs of the generator could be driven back and forth, and the basic operation of the electrostatic converter was confirmed. It was found that a parasitic capacitance of $4.3 \mathrm{pF}$ dominated the operation, for a minimum inherent capacitance of only $1.2 \mathrm{pF}$. Roundy calculates that the device generates $1.4 \mathrm{~nJ}$ per cycle when precharged to $5 \mathrm{~V}$

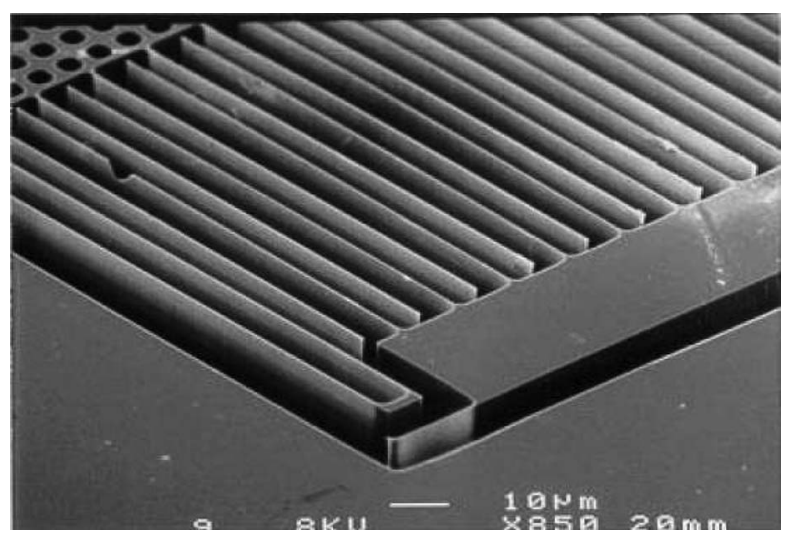

Fig. 19. In-plane generator by Roundy et al. (from [2] with kind permission of Springer Science and Business Media). (corresponding to an input electrical energy of $0.15 \mathrm{~nJ}$ per cycle). This is the first report of a MEMS-based electrostatic generator that includes integrated electronics.

A much larger example of an inertial electrostatic converter is described by Tashiro et al. in [104]. The aim is to create an in vivo power supply for use with a device such as a cardiac pacemaker. The variable capacitor is a honeycomb structure variable between 110 and $32 \mathrm{nF}$ and is attached to a circuit with two rectifiers: one supplying priming energy from a battery and one outputting the generated energy into a storage capacitor. In order to estimate the available acceleration from cardiac motion, the authors attach a three-axis accelerometer directly to the left ventricular wall of a small goat. When the generator, with a resonant frequency of $4.76 \mathrm{~Hz}$ (the third harmonic) and a proof mass of $640 \mathrm{~g}$, is excited by a motion equivalent to that measured from the goat, it produces $58 \mu \mathrm{W}$.

It is possible to run an electrostatic generator without requiring priming by making use of an electret. This technique is described by Sterken et al. in [105]. The electret is placed in parallel with two variable comb drive capacitors operating in antiphase, resulting in charge transfer between the variable capacitors as the proof mass moves. This charge transport drives current into the load. The use of two variable capacitors means that the generated current does not have to flow through the electret capacitor, thus avoiding the low-pass filtering effect of the electret. In later work [106], a modified design is presented where only one variable capacitor is used that has been optimized towards energy generation. The authors have presented results from a working prototype device capable of generating $5 \mathrm{nW}$ from a $500 \mathrm{~Hz}, 3 \mathrm{~mm} / \mathrm{s}$ vibration [107].

A further example of an electrostatic device utilizing an electret is presented by Mizuno and Chetwynd in [108] alongside their electromagnetic generator. The device uses an electret with variable air gap and under testing produced a $16 \mathrm{mV}$ output when excited at the resonant frequency of $743 \mathrm{~Hz}$, with input amplitude of $0.64 \mu \mathrm{m}$. No figure for power output is given, but the authors do state that the source impedance will be high because the capacitance of the electret is very low. The authors suggest using many generators in parallel but conclude that the power output of their device is likely to be too low to be useful.

A working Coulomb force parametric generator has been presented in [109]. The device was fabricated using a three-wafer construction, as shown in Fig. 20. The central wafer contains a silicon proof mass, forming one plate of the variable capacitor, along with a silicon frame and polyimide suspension metallized for electrical contact. Polyimide is chosen to give a very low suspension stiffness to avoid resonant effects. The bottom wafer is glass to minimize parasitic capacitance. Charging and discharging are through studs with which the moving mass makes contact at the ends of its travel, resulting in selfsynchronous operation. Fig. 21 shows the completed 


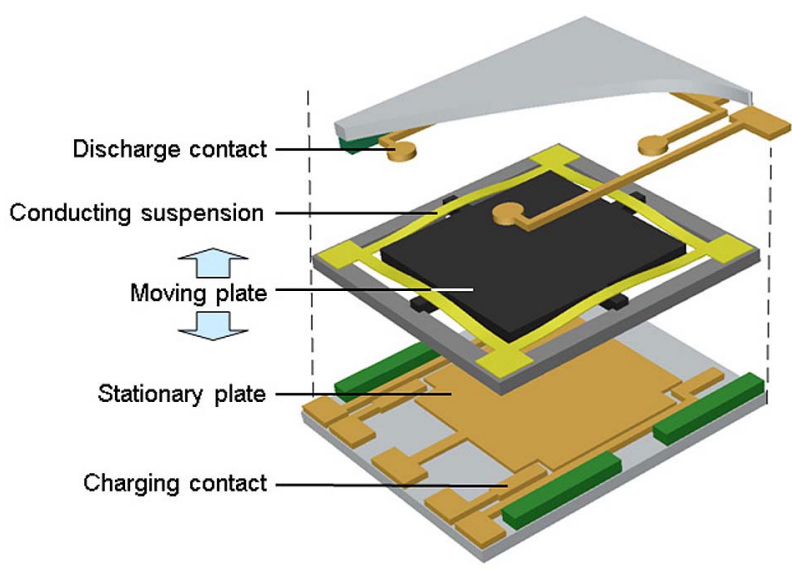

Fig. 20. Exploded view of parametric generator (from [109]).

device, and operational waveforms are shown in Fig. 22. The measured output energy was $120 \mathrm{~nJ}$ per cycle at $30 \mathrm{~Hz}$, with source acceleration of $10 \mathrm{~m} / \mathrm{s}^{2}$. However, the power obtained remains significantly below theoretically achievable values. The authors believe an important limitation is the motion of the proof mass in unwanted degrees of freedom, in particular tilting.

A hybrid low frequency, low intensity vibration energy harvester that couples piezoelectric and electrostatic transduction mechanisms is proposed in [110]. It is an electrostatic oscillator suspended by piezoelectric springs, as shown in Fig. 23. The voltage developed by spring elongation is used to prime the electrostatic transduction.

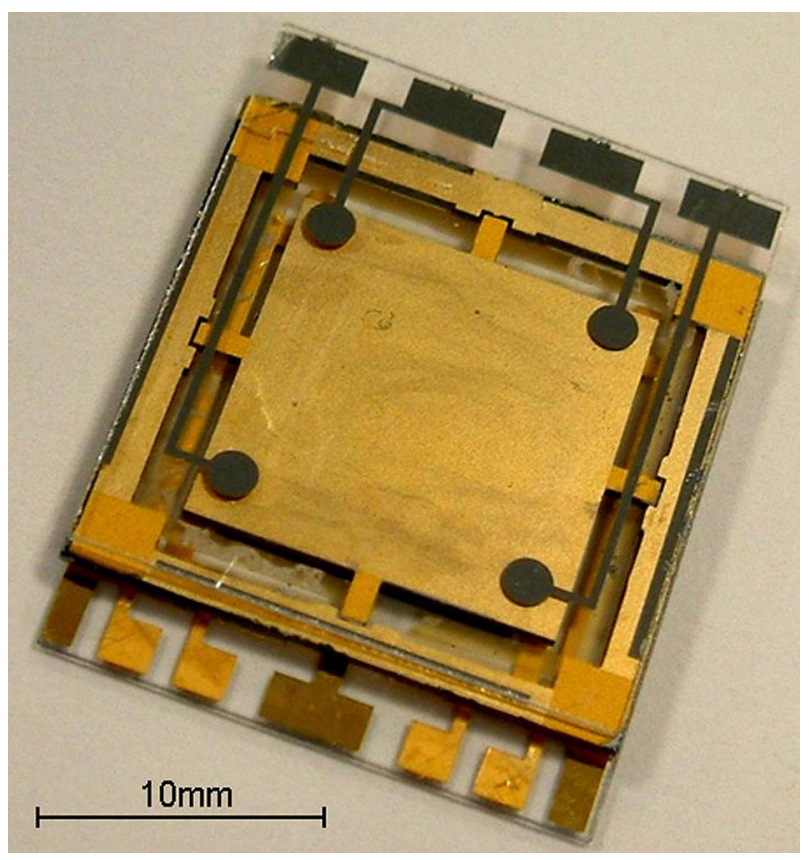

Fig. 21. Prototype parametric generator (from [109]).

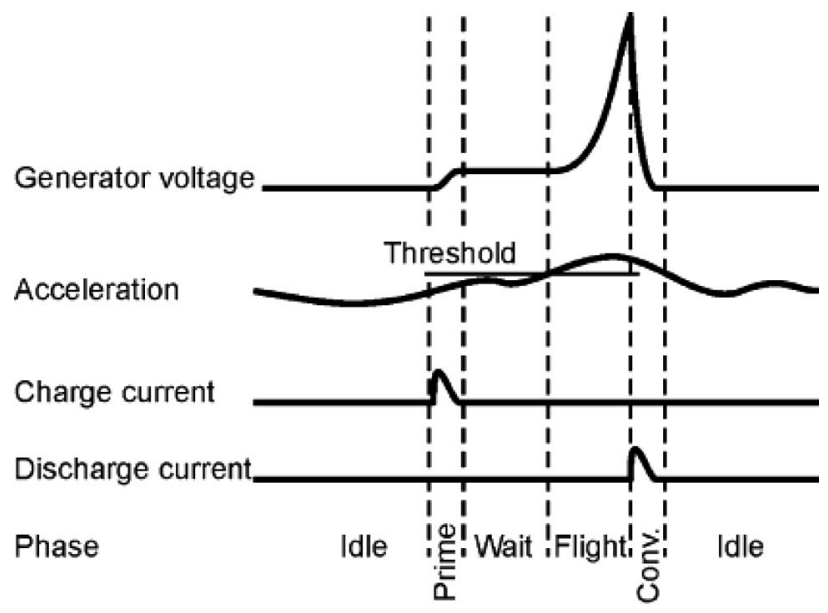

Fig. 22. Parametric generator operational waveforms (from [109]).

The piezoelectric springs also provide control signals for charge and discharge cycles. A block diagram of the hybrid harvester system is shown in Fig. 24.

An electrostatic microgenerator with $100 \mathrm{~Hz}$ bandwidth to harvest energy over a wider spectrum of vibrations is described in [111]. By using an in-plane gap-closing charge-constrained mode, high electrical damping can be achieved. A fabricated macroscale bulk tungsten structure, with a volume of $18 \mathrm{~cm}^{3}$, delivered $1.76 \mathrm{~mW}$ at $50 \mathrm{~Hz}$ and $1 \mathrm{~g}$ acceleration, with a proof mass of $104 \mathrm{~g}$. A flyback power converter is proposed for charging and discharging the variable capacitor.

(a)

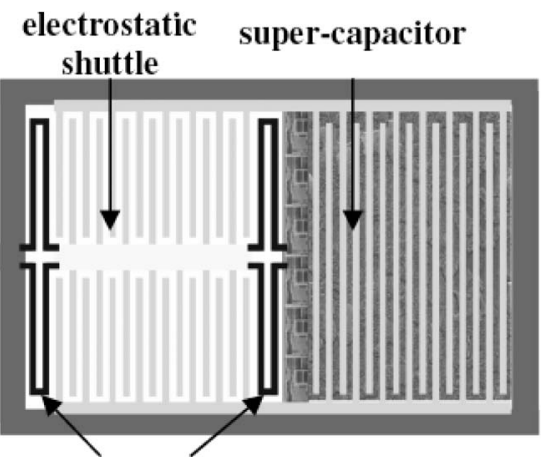

(b)

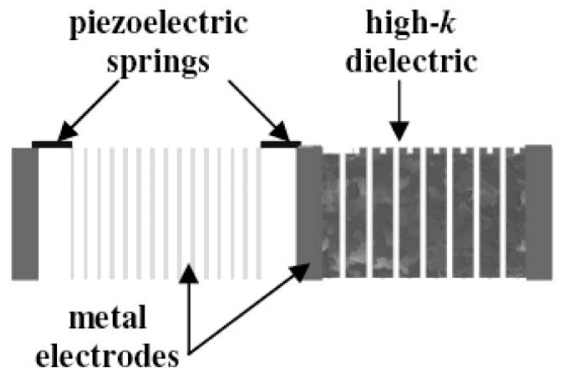

Fig. 23. HALF-LIVES device structure (from [110]). (a) Plan view and (b) elevation. 


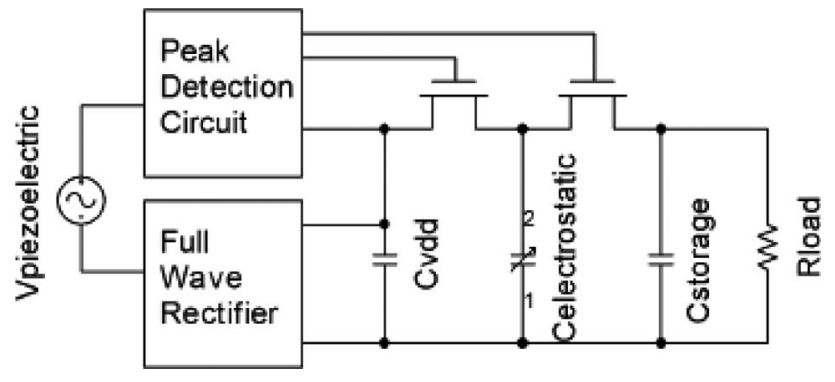

Fig. 24. HALF-LIVES block diagram (from [110]).

\section{Piezoelectric Inertial Generators}

As with the electromagnetic inertial microgenerators, the first instance of reported piezoelectric microgenerators occurs in the patent literature. In [112] and [113], Snyder describes the use of a piezoelectric generator embedded in the wheel of a car to power a tire pressure sensor. The generator would be powered from wheel vibration during driving, and abnormal tire pressure could be reported to the driver using a low-power radio link. Tire pressure monitors have been required on every new car in the United States since September 2007, and consequently this application area is receiving much interest [114].

Segal and Bransky describe a novel application for a piezoelectric inertial generator in [115], and this is the first such device reported in the research literature. The authors suggest using a piezoelectric disk to power the guidance system of a projectile; although batteries are well suited to the short operational life in this application, energy harvesting would avoid the problem of battery discharge during long storage times.

In [116], Elvin et al. discuss a self-powered strain sensor for applications in structural and human health monitoring. A piezoelectric material flexed by a sinusoidal force charges a reservoir capacitor through a half bridge rectifier, and an RF transmitter attached to the reservoir transmits a signal every time the voltage reaches a threshold. Consequently, the time between transmissions decreases as the piezoelectric is subject to higher forces and higher frequency deflections, so that the time between transmissions provides a measurement of strain.

In [117], Sodano et al. build upon previously published models to derive a model of a piezoelectric cantilever that is excited by a sinusoidal acceleration at the clamped end. In [118], Xu et al. describe numerical simulation of a piezoelectric material. The system is described by a parallel conductance and capacitance. This model is in a form that is implementable as a new device level model in SPICE.

In addition to the work described above on electromagnetic generators, piezoelectric devices have also been reported by the University of Southampton [119]. Proposed applications are medical implants and structural monitoring. The authors cite the model of [86] as a suitable ap- proximation but state that hysteretic (or rate-independent) damping is a more suitable model for piezoelectric devices. In order to ease the modelling, the piezoelectric beam was wedge shaped in order that, for a deflection of the beam by a force applied at the tip, the stress throughout the piezoelectric material is constant. The difficulties of fabrication with piezoelectric materials are detailed. The device was tested on a shaker table. The resonant frequency was measured as $80.1 \mathrm{~Hz}$ and the beam motion amplitude as $0.8 \mathrm{~mm}$. The recorded power output from the prototype was $1.5 \mu \mathrm{W}$.

Some of the most significant contributions of Roundy et al. to the field of energy harvesting are in the area of piezoelectric devices. They cite the advantages that the maximum energy density of piezoelectric material is higher than that of either magnetic or electric fields in air [2], and that a piezoelectric generator does not require an initial (priming) charge source as do electrostatic transducers.

In [120], a detailed model of a vibration-driven piezoelectric generator is presented. By calculating an effective moment of inertia for their composite beam, the authors then derive a relationship between the displacement of the tip of the cantilever and the input acceleration. This is dependent upon the stress of the beam, which itself is dependent upon the electric field in the piezoelectric layer. An equation for the power output as a function of the mechanical excitation of the beam is then obtained. This is the first time that such a closed-form expression is presented in the literature. The power output is first found for an optimal resistive load; the equations are then modified to show performance when a full bridge rectifier and smoothing capacitor are added as a first stage of power processing.

In [121], the authors describe the realization of an RF beacon powered by both a solar cell and the optimized piezoelectric generator of [120]. Here $375 \mu \mathrm{W}$ was generated from an acceleration of $2.25 \mathrm{~m} / \mathrm{s}^{2}$ at $60 \mathrm{~Hz}$, corresponding to a displacement amplitude of $16 \mu \mathrm{m}$. When the generator drives a capacitive load through a bridge rectifier, the power decreases by $50 \%$. The radio can be operated at a duty-cycle of $11 \%$ when illuminated in high indoor lighting conditions; the duty-cycle when powered from vibration alone is around $2 \%$. In [122], the authors discuss ideas for improving the power density of piezoelectric generators, concentrating on three main methods: employing an actuator for tuning the resonant frequency; using multi-mass-spring systems to improve the bandwidth; and changing the geometry of the beam to reduce parasitic damping and improve robustness. The authors also suggest that higher efficiencies could be achieved through better integration of the mechanical generator and power electronics.

In [123], Hammond et al. describe a working selfpowered TinyTemp node, $20 \mathrm{~cm}^{3}$ in volume (Fig. 25). This device was designed, in a collaboration with the California Energy Commission, as part of a building-wide sensor network to facilitate fine-grained temperature control to 
(a)
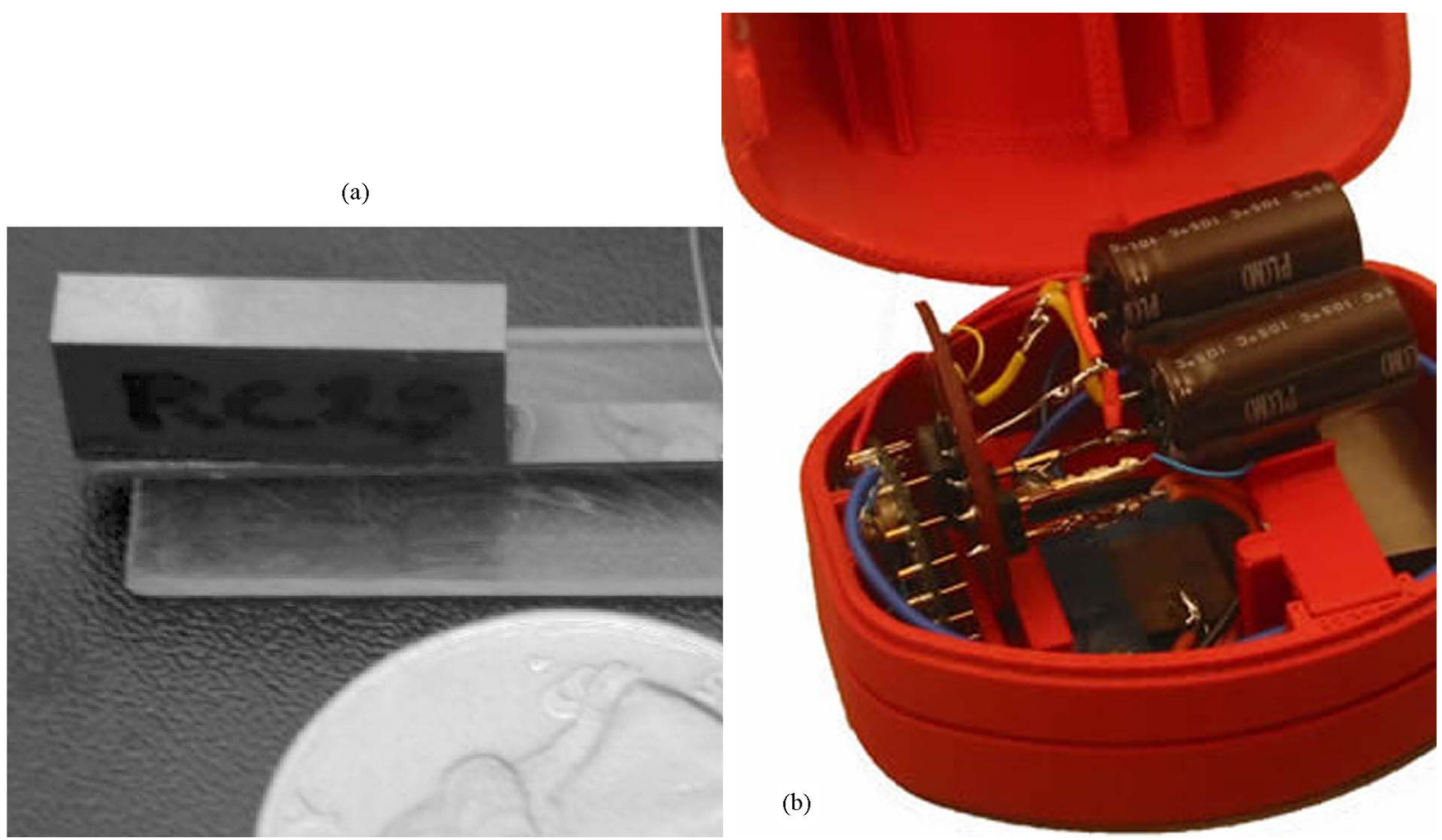

Fig. 25. (a) Piezoelectric generator and (b) self-powered sensor node (from [120] and [123]).

increase personal comfort and energy efficiency. The difficulty of using piezoelectric materials with standard MEMS and complementary metal-oxide-semiconductor processing techniques is described, along with a new process from Motorola that significantly improves process compatibility. Design and fabrication of thin-film piezoelectric unimorphs is described in [124]. A cantilever beam of $800 \times 800 \mu \mathrm{m}^{2}$ with a proof mass of $24.7 \mathrm{pg}$ on the beam tip developed $5 \mathrm{mV}$ and $24.5 \mathrm{pW}$. The initial prototype power density was $13 \mu \mathrm{W} / \mathrm{cm}^{3}$.

Energy conversion efficiency for rectified piezoelectric power harvesters has been studied in [125]. The relationships among energy efficiency, electrically induced damping, and ac-dc power output are established explicitly. It is shown that the optimization criteria depend on the coupling strength. A comprehensive review of recent piezoelectric power harvesting research is provided in [126].

\section{E. Energy Harvester Performance Metrics}

A key issue in the discussion of energy harvesters is what performance metrics, or figures of merit, are appropriate to compare different devices or design approaches. Power efficiency could be defined for a harvester as the ratio of electrical power out to mechanical power in, but while this would give some indication of the effectiveness of the transduction, it misses a key aspect-namely, that the input mechanical power itself strongly depends on the device design. On the other hand, we cannot easily define the efficiency in terms of the potential mechanical power available from the source since typically this is effectively limitless, i.e., loading by the harvester has a negligible effect on the source. Instead, the maximum output of the harvester is normally a function of its own properties, particularly its size.

Various metrics other than efficiency have been proposed, including power density [127], normalized power density [128], and two proposed measures of effectiveness [62], [129]. Power density is attractive because this measure is very important to the end user; however, it only provides a meaningful comparison for fixed vibration source characteristics, since attainable output is so dependent on these, as shown in (2). Also, if specific source characteristics are used to compare two devices, they should each have been optimized with such a source in mind.

To reach a more universal metric, a possible normalized power density (with respect to source characteristics) is given in [128], in which the power density is divided by source acceleration amplitude squared. There are three difficulties with this approach. First, it is desirable to have performance metrics with a maximum value of unity, so that it is clear how close the design is to optimality. Secondly, maximum power is proportional to acceleration squared divided by frequency, so the source dependence has not been fully removed. Thirdly, since attainable power is proportional to mass times internal displacement range, or to volume $e^{4 / 3}$, dividing by volume does not remove the size dependence completely and thus favors larger devices.

In [129], Roundy proposes a dimensionless figure of merit called effectiveness to compare power output of 
various transduction mechanisms

$$
e=\left(k^{2}\right) Q^{2}\left(\frac{\rho}{\rho_{o}}\right)\left(\frac{\lambda}{\lambda_{\max }}\right)
$$

where $e$ is the effectiveness, $k^{2}$ is a coupling coefficient of the transduction mechanism, $Q$ is the quality factor of the design, $\rho_{o}$ is a baseline material density, $\rho$ is the actual density of the device, $\lambda$ is the transmission coefficient, and $\lambda_{\max }$ the maximum transmission coefficient of the transduction mechanism. Broad comparison of harvester designs is possible with this metric, but it does not have a defined maximum value, since $Q$ has no fundamental limit, and so it does not directly indicate how close a device is to optimal performance.

An alternative definition of effectiveness is introduced in [62], which we here label harvester effectiveness

$$
\begin{aligned}
E_{H} & =\frac{\text { Useful Power Output }}{\text { Maximum Possible Output }} \\
& =\frac{\text { Useful Power Output }}{\frac{1}{2} Y_{0} Z_{l} \omega^{3} m} .
\end{aligned}
$$

The harvester effectiveness as defined above has a theoretical maximum of $100 \%$ and is mainly a measure of how closely a specific design approaches its ideal performance; it does not distinguish between designs of different proof mass density or geometry. For this reason, we introduce here a variant of this metric, which we term the volume figure of merit $\mathrm{FoM}_{V}$, which aims to compare the performance of devices as a function of their overall size. This is done by substituting the actual $m$ and $Z_{l}$ of the devices with values for an equivalent device of cubic geometry, having the same total package volume but with a proof mass, with the density of gold $\left(\rho_{A u}\right)$, occupying half this volume, and space for displacement occupying the other half. Such a device has a maximum power as indicated in Fig. 7. This gives

$$
\mathrm{FoM}_{V}=\frac{\text { Useful Power Output }}{\frac{1}{16} Y_{0} \rho_{A u} V_{o} l^{\frac{4}{3}} \omega^{3}}
$$

A real device of cubic geometry could not reach an $\mathrm{FoM}_{V}$ of $100 \%$, since some space must be taken up by the frame, suspension, and transducer components. However, since elongation of the device along the motion axis can increase the power density, the value for a noncubic device can in principle exceed $100 \%$.

Tables 1-3 present a summary of the important parameters of reported inertial energy harvesters. The devices are presented in the order that they appear in the discussion above, and the research team is identified by the first author on the corresponding paper(s). Only papers reporting experimental results are included in the tables. Several observations can be made from the reported data.

- $\quad$ There has been significantly more work presented on electromagnetic generators than on the other two types.

- The typical size of electromagnetic generators has been shrinking over the last decade.

- Around half of the reported work contains information regarding models of microgenerators, the other half giving measured results of prototypes. There are six cases where results of a model and a prototype are presented; of these, the piezoelectric generator by Roundy et al. achieves the closest match between the model and measurements.

- The designed operating frequency of most devices, independent of transducer type, is $50-200 \mathrm{~Hz}$. Only three groups - Tashiro et al., Kulah et al., and our own-have attempted to design inertial microgenerators to operate at frequencies below $5 \mathrm{~Hz}$.

- There is a large variation in the amplitudes of the motion used to drive the generators, ranging from less than $1 \mathrm{~nm}$ to several millimeters. Generally, generators designed to work at higher frequencies are driven by lower displacement amplitude sources.

In Fig. 26, volume figure of merit is plotted against year of publication. While there is considerable scatter, the general trend is increasing, although at least a further order of magnitude improvement should be possible. Fig. 27 shows that harvester effectiveness values are mostly in the $1-10 \%$ range, with the best value over $30 \%$. It can also be seen that the smallest devices have poor effectiveness, indicating the difficulty involved in microengineered implementations. In general, no obvious trends can be discerned about the relative merits of the different transducer types. Fig. 28 gives harvester effectiveness replotted against operating frequency and shows the reduced values at high frequency, which is probably a result of the need for higher mechanical $Q$ in these devices and the stronger influence of parasitic damping.

An important factor that is not captured by the metrics used above is bandwidth of operation. For applications where the device size is greater than the source motion amplitude, high $\mathrm{Q}$ operation is generally needed to maximize output power, and this entails the penalty of reduced frequency range of operation. However, the frequency range over which a device can extract power effectively is an important consideration for most applications. For this reason, we propose a further figure of merit, the bandwidth figure of merit, which is simply the volume figure of merit times the fractional bandwidth

$$
\mathrm{FoM}_{\mathrm{BW}}=\mathrm{FoM}_{V} \times \frac{\delta \omega_{1 \mathrm{~dB}}}{\omega}
$$


Table 1 Comparison of Effectiveness of Published Electromagnetic Motion Harvesters

\begin{tabular}{|c|c|c|c|c|c|c|c|c|c|c|c|}
\hline Author & Reference & $\begin{array}{l}\text { Generator } \\
\text { Volume } \\
{\left[\mathrm{cm}^{3}\right]}\end{array}$ & $\begin{array}{l}\text { Proof } \\
\text { Mass } \\
\text { [g] }\end{array}$ & $\begin{array}{l}\text { Input Am- } \\
\text { plitude } \\
{[\mu \mathrm{m}]}\end{array}$ & $\begin{array}{l}\text { Input } \\
\text { Fre- } \\
\text { quency } \\
{[\mathrm{Hz}]}\end{array}$ & $Z_{l}[\mu \mathrm{m}]$ & $\begin{array}{l}\text { Power (un- } \\
\text { processed) } \\
{[\mu \mathrm{W}]}\end{array}$ & 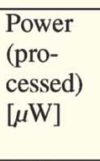 & $\begin{array}{l}\text { Power } \\
\text { Density } \\
{\left[\mu \mathrm{W} / \mathrm{cm}^{3}\right]}\end{array}$ & $\begin{array}{l}\text { Harvester } \\
\text { Effec- } \\
\text { tiveness } \\
{[\%]}\end{array}$ & $\begin{array}{l}\text { Volume } \\
\text { Figure } \\
\text { of } \\
\text { Merit } \\
{[\%]}\end{array}$ \\
\hline $\mathrm{Li}$ & [91] & 1.00 & 0.22 & 200 & 60 & 5000 & & 100 & 100 & 1.70 & 0.08 \\
\hline $\mathrm{Li}$ & [91] & 1.00 & 0.22 & 200 & 120 & 1000 & & 100 & 100 & 1.07 & 0.01 \\
\hline Ching & [130] & 1.00 & & 210 & 107 & & 1.50 & & 1.50 & & $\frac{0.2}{10^{-3}} \times$ \\
\hline Ching & [130] & 1.00 & & 190 & 104 & & 5.00 & & 5.00 & & $\begin{array}{l}0.8 \times \\
10^{-3}\end{array}$ \\
\hline $\mathrm{Li}$ & [131] & 1.24 & 210 & 100 & 64 & & & 10 & 8.06 & & 0.01 \\
\hline Williams & [89] & 0.02 & $2.4 \times$ & 0.50 & 4400 & 63 & 0.33 & & 22 & 0.04 & $10^{-5} \times$ \\
\hline El-hami & [132] & 0.24 & 0.50 & 25 & 322 & 940 & 530 & & 2208.3 & 1.09 & 0.14 \\
\hline Ching & [133] & 1.00 & & 200 & 60 & & & 680 & 680 & & 0.52 \\
\hline Ching & [133] & 1.00 & & 200 & 110 & & & 680 & 680 & & 0.08 \\
\hline Ching & [92] & 1.00 & & 200 & 60 & & & 830 & 830 & & 0.64 \\
\hline Ching & [92] & 1.00 & & 200 & 110 & & & 830 & 830 & & 0.1 \\
\hline Mizuno & [108] & 2.10 & 0.54 & 0.64 & 700 & 6.5 & $0.4 \times 10^{-3}$ & & $\begin{array}{ll}0.2 & \times \\
10^{-3} & \end{array}$ & $\begin{array}{l}0.42 \\
10^{-3}\end{array} \times$ & $\begin{array}{l}2.26 \times \\
10^{-6}\end{array}$ \\
\hline Lee & {$[134]$} & 7.30 & 0.14 & 150 & 85 & 7500 & 830 & & 114 & 6.92 & 0.02 \\
\hline $\begin{array}{l}\text { Glynne- } \\
\text { Jones }\end{array}$ & [135] & 0.84 & & 13 & 322 & 360 & 37 & & 44.0 & & 0.003 \\
\hline Beeby & [136] & 0.10 & 0.03 & $5.4 \times 10^{-3}$ & 9500 & 500 & 0.02 & & 0.21 & $\begin{array}{l}2.6 \\
10^{-3}\end{array} \times$ & $\begin{array}{l}3.27 \times \\
10^{-5}\end{array}$ \\
\hline Beeby & [137] & 0.06 & 0.44 & 0.62 & 350 & 217 & 2.85 & & 47.5 & 0.90 & 0.15 \\
\hline Beeby & [137] & 0.07 & 0.03 & $\begin{array}{l}0.98 \\
10^{-3}\end{array}$ & 9500 & 240 & 0.12 & & 1.79 & 0.02 & $\begin{array}{l}0.174 \times \\
10^{-3}\end{array}$ \\
\hline Serre & [138] & 0.68 & 1.56 & 3.40 & 360 & & 0.05 & & 0.07 & & $1.6 \times$ \\
\hline Saha & {$[96]$} & & 43 & 115 & 13.1 & 1250 & 2000 & & & & \\
\hline Saha & [96] & & 25 & 28 & 84 & 1500 & 3200 & & & & \\
\hline Huang & [139] & 0.04 & 0.03 & 50 & 100 & 5200 & 1.44 & & 40 & 0.14 & 0.08 \\
\hline Perpetuum & [140] & 131 & & 0.633 & 99 & & & 800 & 6.1 & & 0.065 \\
\hline Perpetuum & {$[140]$} & 131 & & 2.54 & 99 & & & 3500 & 27 & & 0.07 \\
\hline Perpetuum & [140] & 131 & & 25.4 & 99 & & & 40000 & 306 & & 0.08 \\
\hline $\begin{array}{l}\text { Ferro Solu- } \\
\text { tions }\end{array}$ & [141] & 133 & & 1.73 & 60 & & 800 & & 6.0 & & 0.1 \\
\hline $\begin{array}{l}\text { Ferro Solu- } \\
\text { tions }\end{array}$ & [141] & 133 & & 3.45 & 60 & & 3100 & & 23 & & 0.2 \\
\hline $\begin{array}{l}\text { Ferro Solu- } \\
\text { tions }\end{array}$ & [141] & 133 & & 6.9 & 60 & & 10800 & & 81 & & 0.35 \\
\hline
\end{tabular}

Table 2 Comparison of Effectiveness of Published Electrostatic Motion Harvesters

\begin{tabular}{|c|c|c|c|c|c|c|c|c|c|c|c|}
\hline Author & Reference & $\begin{array}{l}\text { Generator } \\
\text { Volume } \\
{\left[\mathrm{cm}^{3}\right]}\end{array}$ & $\begin{array}{l}\text { Proof } \\
\text { Mass } \\
\text { [g] }\end{array}$ & $\begin{array}{l}\text { Input Am- } \\
\text { plitude } \\
{[\mu \mathrm{m}]}\end{array}$ & $\begin{array}{l}\text { Input } \\
\text { Fre- } \\
\text { quency } \\
{[\mathrm{Hz}]}\end{array}$ & $Z_{l}[\mu \mathrm{m}]$ & $\begin{array}{l}\text { Power (un- } \\
\text { processed) } \\
{[\mu \mathrm{W}]}\end{array}$ & 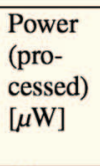 & $\begin{array}{l}\text { Power } \\
\text { Density } \\
{\left[\mu \mathrm{W} / \mathrm{cm}^{3}\right]}\end{array}$ & $\begin{array}{l}\text { Harvester } \\
\text { Effec- } \\
\text { tiveness } \\
{[\%]}\end{array}$ & $\begin{array}{l}\text { Volume } \\
\text { Figure } \\
\text { of } \\
\text { Merit } \\
{[\%]}\end{array}$ \\
\hline Tashiro & [104] & & 640 & 380 & 4.76 & 19000 & & 58 & & 0.09 & \\
\hline Tashiro & {$[142]$} & 15 & 780 & 9000 & 6 & & 36 & & 2.42 & & 0.02 \\
\hline Mizuno & {$[108]$} & 0.6 & 0.7 & 0.64 & 743 & 4.9 & $7.4 \times 10^{-6}$ & & $\begin{array}{l}1.23 \\
10^{-3}\end{array}$ & $\begin{array}{l}6.6 \\
10^{-6}\end{array} \times$ & $\begin{array}{l}1.86 \times \\
10^{-9}\end{array}$ \\
\hline Miyazaki & {$[143]$} & & 5 & 1 & 45 & 30 & & 0.21 & & 12.4 & \\
\hline Arakawa & [144] & 0.4 & 0.65 & 1000 & 10 & 1000 & 6 & & 15 & 7.42 & 0.68 \\
\hline Despesse & [145] & 18 & 104 & 90 & 50 & 90 & 1760 & 1000 & 56 & 7.66 & 0.06 \\
\hline Yen & [146] & & & & 1500 & & & 1.8 & & & \\
\hline Tsutsumino & [147] & & & 600 & 20 & 600 & 278 & & & & \\
\hline Tsutsumino & {$[148]$} & & & 1000 & 20 & 1000 & 6.4 & & & & \\
\hline Mitcheson & [109] & 0.6 & 0.12 & 1130 & 20 & 100 & 2.4 & & 4 & 17.9 & 0.02 \\
\hline
\end{tabular}

We have chosen the $1 \mathrm{~dB}$ bandwidth, i.e., the frequency range within which the output power is less than $1 \mathrm{~dB}$ below its maximum value; as opposed to the more common $3 \mathrm{~dB}$ figure, $\delta \omega_{1 \mathrm{~dB}}$ gives greater credit to devices with flatter frequency response, which is likely to include tunable devices. We have not included this metric in the tables or figures because information on frequency range is rarely available in published reports, but presentation of 
Table 3 Comparison of Effectiveness of Published Piezoelectric Motion Harvesters

\begin{tabular}{|c|c|c|c|c|c|c|c|c|c|c|c|}
\hline Author & Reference & $\begin{array}{l}\text { Generator } \\
\text { Volume } \\
{\left[\mathrm{cm}^{3}\right]}\end{array}$ & $\begin{array}{l}\text { Proof } \\
\text { Mass } \\
{[\mathrm{g}]}\end{array}$ & $\begin{array}{l}\text { Input Am- } \\
\text { plitude } \\
{[\mu \mathrm{m}]}\end{array}$ & $\begin{array}{l}\text { Input } \\
\text { Fre- } \\
\text { quency } \\
{[\mathrm{Hz}]}\end{array}$ & $Z_{l}[\mu \mathrm{m}]$ & $\begin{array}{l}\text { Power (un- } \\
\text { processed) } \\
{[\mu \mathrm{W}]}\end{array}$ & 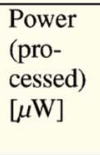 & $\begin{array}{l}\text { Power } \\
\text { Density } \\
{\left[\mu \mathrm{W} / \mathrm{cm}^{3}\right]}\end{array}$ & $\begin{array}{l}\text { Harvester } \\
\text { Effec- } \\
\text { tiveness } \\
{[\%]}\end{array}$ & $\begin{array}{l}\text { Volume } \\
\text { Figure } \\
\text { of } \\
\text { Merit } \\
{[\%]}\end{array}$ \\
\hline $\begin{array}{l}\text { Glynne- } \\
\text { Jones }\end{array}$ & [149] & 0.53 & & & 80.1 & 800 & 1.5 & & 2.83 & & \\
\hline Roundy & [2] & 1 & 8.5 & 4 & 120 & 150 & 80 & & 80 & 7.3 & 0.39 \\
\hline Roundy & [2] & 1 & 7.5 & 7.9 & 85 & 143 & 207 & 90 & 90 & 14 & 0.62 \\
\hline Roundy & [2] & 1 & 8.2 & 16 & 60 & 150 & 365 & 180 & 180 & 34 & 1.74 \\
\hline Wright & $\begin{array}{l}{[2],} \\
{[123]}\end{array}$ & 4.8 & 52.2 & 36 & 40 & & 1700 & 700 & 145 & & 1.25 \\
\hline Lefeuvre & {$[150]$} & 113 & 228 & & 56 & 2000 & & 10000 & 88 & & \\
\hline Lefeuvre & {$[150]$} & 113 & 228 & & 56 & 2000 & & 300000 & 2650 & & \\
\hline Lefeuvre & {$[151]$} & & & & Random & & & & 15000 & & \\
\hline Tanaka & {$[152]$} & 9 & & 10 & 50 & & 180 & & 20 & & 0.26 \\
\hline Fang & {$[153]$} & 0.0006 & 0.0015 & 4.4 & 609 & & 2.16 & & 3510 & & 1.39 \\
\hline Elvin & [154] & 0.101 & 1.2 & $\begin{array}{l}\text { earth } \\
\text { quake } \\
\text { spectrum }\end{array}$ & 0.5 & 2000 & 0.25 & & 2.47 & & \\
\hline Duggirala & {$[155]$} & & & & 38 & & 0.17 & & & & \\
\hline Duggirala & [155] & & & & 38 & & 1.13 & & & & \\
\hline Jeon & {$[156]$} & & & 32.5 & 13900 & 2.56 & 1 & & & & \\
\hline $\mathrm{Ng}$ & {$[157]$} & 0.20 & 0.96 & 184 & 100 & & 35.5 & 16.3 & 82 & & 0.03 \\
\hline Ferrari & {$[158]$} & & 82 & 0.053 & 41 & & & 0.27 & & & \\
\hline Mide & {$[159]$} & 40.5 & & 99 & 50 & & & 8000 & 198 & & 0.16 \\
\hline Mide & [159] & 40.5 & & 11 & 150 & & & 1800 & 45 & & 0.012 \\
\hline
\end{tabular}

such data in future publications would be of considerable value to the research and user communities.

\section{ENERGY HARVESTING USING AIR FLOW}

The use of ambient airflow to power wireless sensors has received little attention to date, which is perhaps surprising given the relatively high power densities that can be achieved. The kinetic energy per unit volume in a fluid flowing at speed $U$ is $1 / 2 \rho U^{2}$, where $\rho$ is the fluid density. This corresponds to a power flow of $1 / 2 \rho U^{3}$ per unit

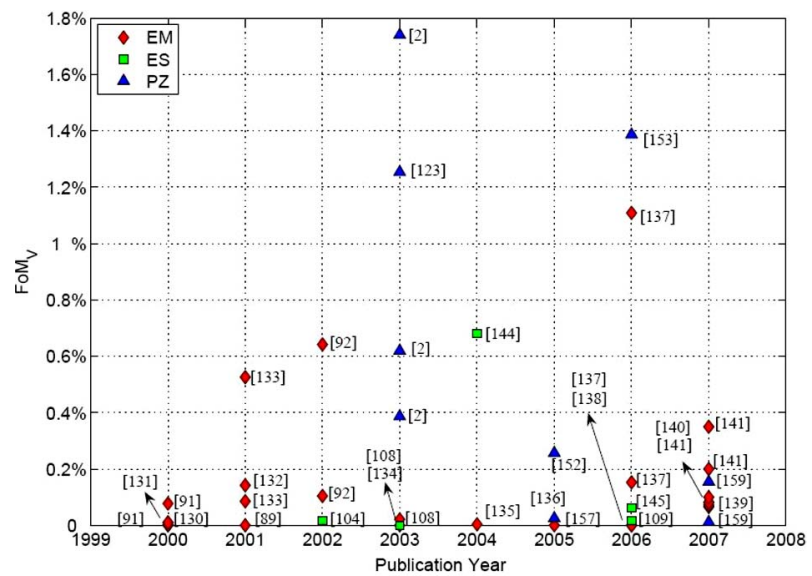

Fig. 26. Volume figure of merit versus year of publication for reported motion energy harvesters as indicated. area normal to the flow. An energy extraction device placed in the flow cannot extract all of this power, since if it did the fluid intercepted by the device would be brought to rest and could not be removed from the downstream side. The power extracted by a device of area $A$ may therefore be expressed as $P_{\text {out }}={ }_{1} / 2 C_{P} \rho A U^{3}$, where $C_{P}$ is a power coefficient less than unity. It can be shown from basic conservation laws that, for an ideal energy extraction device, $C_{P}$ has a theoretical maximum of $16 / 27=0.593$, the so-called Betz limit [160], with real devices achieving lower $C_{P}$ values as a result of losses.

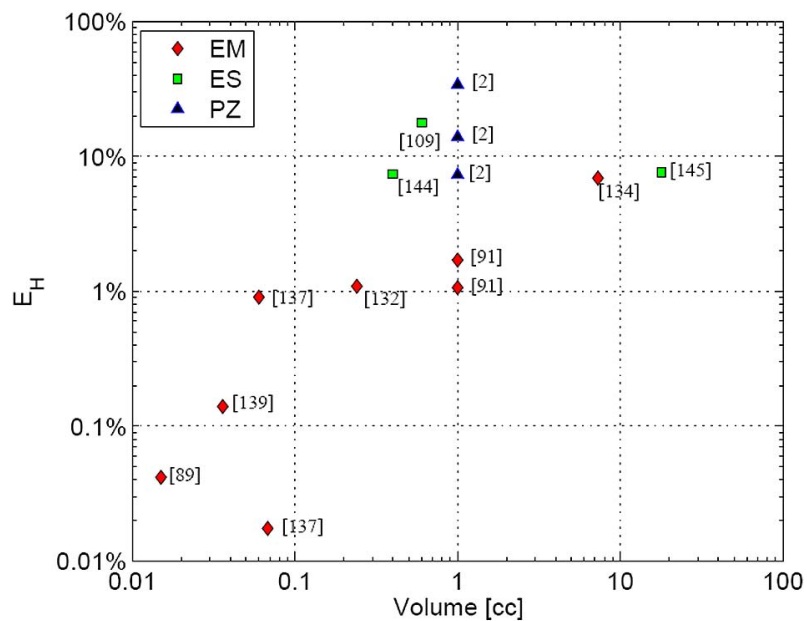

Fig. 27. Harvester effectiveness of reported devices versus device volume. 


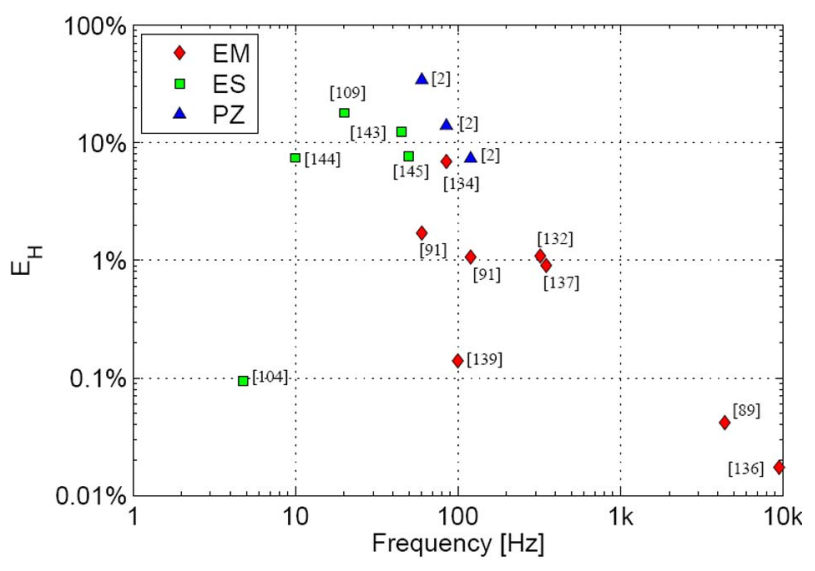

Fig. 28. Harvester effectiveness of reported devices versus operating frequency.

The best known device for extracting power from airflows on a large scale is the wind turbine, and miniaturization of this device is a natural starting point for airflow harvesting on a smaller scale. Large-scale wind turbines can be highly efficient, with power coefficients greater than 0.5 being achievable. However, the performance of miniature wind turbines is expected to be less good, primarily because of the relatively high viscous drag on the blades at low Reynolds numbers [161]. Other factors such as bearing losses will also tend to lower the efficiency in small devices. Fig. 29 shows the variation of output power per unit area with flow rate for a device operating at the Betz limit and for a device with a relatively conservative $C_{P}$ value of 0.1 . An air density of $1.2 \mathrm{~kg} / \mathrm{m}^{3}$ is assumed. At the lower $C_{P}$ value, a power density of $750 \mu \mathrm{W} / \mathrm{cm}^{2}$ is obtained at a flow rate of $5 \mathrm{~m} / \mathrm{s}$, decreasing to $6 \mu \mathrm{W} / \mathrm{cm}^{2}$ at $1 \mathrm{~m} / \mathrm{s}$. From these values, it seems that centimeter-scale energy harvesters should be able to generate useful amounts of

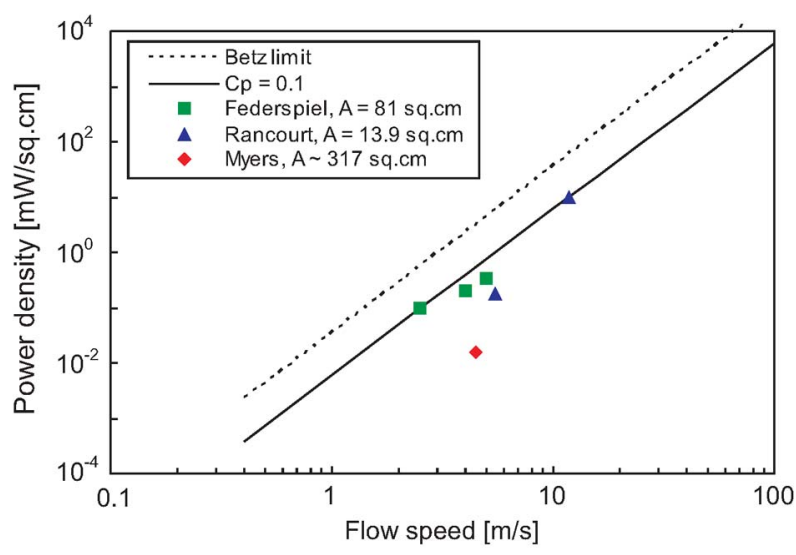

Fig. 29. Energy harvesting from airflow: expected power output as a function of flow speed and results for some prototype devices. power where modest ambient flows are present, for example, in air-conditioning ducts, in outdoor environments, or on moving vehicles.

In recent years, several groups have demonstrated small airflow harvesters based on the wind turbine principle. For example, Federspiel and Chen [162] combined a 4-in-diameter fan rotor, a brushless dc motor operated as a generator, and a three-phase bridge circuit to produce a device that could deliver up to $28 \mathrm{~mW}$ at $5.1 \mathrm{~m} / \mathrm{s}$ flow rate or $8 \mathrm{~mW}$ at $2.5 \mathrm{~m} / \mathrm{s}$. More recently, Rancourt et al. [163] have demonstrated a smaller device, with a $4.2-\mathrm{cm}$ diameter rotor, that delivers powers of 2.4 and $130 \mathrm{~mW}$ at flow rates of 5.5 and $12 \mathrm{~m} / \mathrm{s}$, respectively. In both cases, existing commercial rotor and generator parts were used. Myers et al. [164] have developed a custom piezoelectric generator, which, when coupled to three 5-in-diameter fan rotors via a crank assembly, can deliver $5 \mathrm{~mW}$ of output power at a flow rate of $4.4 \mathrm{~m} / \mathrm{s}$. The relative performances of these three devices are compared in Fig. 29.

While the results discussed above are encouraging, they are for relatively large devices, which may not be appropriate for many wireless sensor applications. Only one smaller scale airflow harvester has been reported to date. This device, shown in Fig. 30, was realized using MEMS technology [165] and was aimed at higher flow-rate applications. It comprises a 12-mm-diameter axial-flow turbine integrated with an axial-flux electromagnetic generator. Although it was not tested in a free stream, duct tests showed that an output power of $1 \mathrm{~mW}$ could be delivered at a volume flow of $35 \mathrm{l} / \mathrm{min}$ and a pressure drop of $8.4 \mathrm{mbar}$. For operation in a free stream, the same output power would be expected at a flow speed of around $40 \mathrm{~m} / \mathrm{s}$.

In addition to focusing on the design of more efficient centimeter-scale turbines, ongoing work on airflow harvesters will need to address the problem of operation at

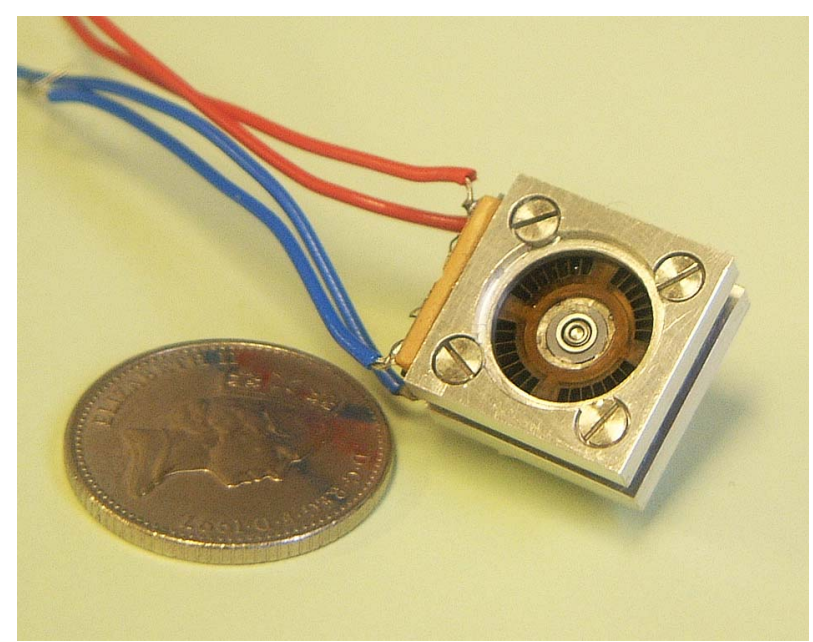

Fig. 30. MEMS airflow harvester, with 10 pence coin for scale (from [165]). 
very low flow rates. In order to be useful in a wide range of applications, airflow harvesters will need to operate at flow speeds down to about $1 \mathrm{~m} / \mathrm{s}$; for this to be possible with turbines, very low-friction bearing solutions will need to be found. Because of this limitation, alternative approaches to airflow harvesting based on flapping or vibrating elements, that can avoid the use of bearings, are also likely to receive increased attention in future. Such approaches have previously been used in flow measurement and are currently being developed for larger scale power generation.

\section{POWER ELECTRONICS FOR MICROPOWER GENERATORS}

There are two key reasons why conditioning of the output power of a micropower generator is called for. First, it is very unlikely that the unprocessed output of the transducer will be directly compatible with the load electronics. Secondly, in most cases it is desirable to maximize the power transfer from the transducer by optimizing the apparent impedance of the load presented to it. It may also be necessary to provide energy storage for sources that are intermittent or for relatively high power loads that run in burst mode.

It is clear from the literature to date that much more attention has been paid to the transducer itself than the power conditioning. Most researchers have used a simple resistive load to determine the electrical power output of their transducers. Some perform simple processing by bridge rectifiers and smoothing capacitors, and only a small number of publications describe more sophisticated power processing stages with voltage regulation or power transfer optimization.

Most of the work on power electronics for motion harvesters has been for piezoelectric transducers, where the transducer voltage is relatively high. A first report of this by Shenck [78] addresses the direct-force piezoelectric generator in a running shoe. It was found that a direct discharge by connection to a rectifier and smoothing capacitor does not extract maximum power. Instead it is necessary to switch the connection between generator and processing circuit so that the limited charge of the piezoelectric material is removed only when it has reached maximum voltage, thereby maximizing the energy obtained. A step-down switch-mode power supply (incorporating a transformer to allow a reasonable duty cycle for the large conversion ratio) was appended to regulate the output voltage.

The optimization of power transfer through impedance matching was first discussed in a piezoelectric design by Ottman et al. in [166]. The piezoelectric element was modelled as a sinusoidal current source and parallel capacitor. Tests showed that constant model parameters could be used for a range of loads at the resonant frequency. The transducer is connected to a full-bridge diode rectifier and smoothing capacitor with the capacitor volt- age varied to maximize power transfer. The optimal voltage is found to be a function of the mechanical excitation and so adaptive control of the voltage is required. For a battery charging application, a dc-dc converter is proposed and maximum power transfer is obtained by maximizing the output current (into the near constant output voltage) through iterative adjustment of the duty cycle of the converter. Experimental results from a piezoelectric bimorph mounted on a shaker closely match the theory. The adaptive controller takes 6 min to settle at the optimal duty cycle and achieves a maximum efficiency of $88 \%$. The maximum harvested power of the converter was around $70 \mathrm{~mW}$ (not accounting for the consumption of the controller itself). Calculation of the optimal duty cycle was adopted in [167] to avoid iterative controllers. With this approach, the power consumption of the controller itself was $5.74 \mathrm{~mW}$, and again experimental results confirmed the theory. Maximum power output was $24 \mathrm{mw}$ from a transducer output of $30 \mathrm{mw}$. At low excitation, the controller is bypassed to avoid consuming all the generated power. Kim et al. in [80] showed an experimental approach to finding an optimal duty cycle for a switch-mode power converter, but without supporting theory.

In [168], Le et al. note that the diode rectifier used in [166] and [167] will cause voltage drops that lose significant power at the low transducer voltages possible in a microgenerator, and go on to investigate charge pump and voltage multiplier circuits which use MOSFET synchronous rectifiers in place of diodes. Because the piezoelectric material has a series capacitance, a half-wave voltage doubler that makes use of that capacitance is easily incorporated into the rectifier. The synchronous half-wave voltage doubler is shown to obtain the highest output power of all the techniques tried. The authors use an arbitrary waveform generator and a series $\mathrm{RC}$ circuit to simulate the output of the piezoelectric device to conduct tests. They report a maximum useful power output of $18.8 \mu \mathrm{W}$ at a power processing efficiency of $92 \%$, but the details of excitation are not given. The use of charge pumps to increase the transducer output voltage is also presented by James et al. in [94] and Ching and Li et al. in [91], [92], [130], [131], and [133] for electromagnetic generators. James et al. note that this technique is superior to using a transformer not only in terms of electrical efficiency but also because of constraints on size and weight.

In [169], Le et al. describe a circuit for interfacing with a pressure-excited piezoelectric membrane. The membrane had a resonant frequency of $340 \mathrm{~Hz}$ with a significant second-harmonic output, and the maximum open circuit voltage is around $1 \mathrm{~V}$. An equivalent circuit of two sinusoidal voltage sources in series and a parallel RC circuit was developed. The low voltage and relatively high output impedance of the transducer are cited as the main difficulties in designing the power electronics. A halfbridge synchronous rectifier and capacitive voltage doubler were used and controlled by a circuit using FETs 
in subthreshold mode. In simulation, an efficiency of more than $90 \%$ was obtained for current greater than $4 \mu \mathrm{A}$ from about output voltage of $0.5 \mathrm{~V}$ (with a $0.2 \mathrm{~V}$ output ripple). Among suggested modifications, a full-bridge synchronous rectifier with active control is found to be the most efficient.

In [2], Roundy et al. provide analysis that shows the maximum available power from a piezoelectric converter is greater with a resistive load than with a capacitive load connected through a full-bridge diode rectifier. Roundy's results agree with those of Ottman et al. for the rectifier and capacitor case in that the maximal power transfer occurs when the voltage on the smoothing capacitor is half of the open circuit voltage of the piezoelectric element (assuming that the smoothing capacitor is large compared to the series capacitance of the transducer). The authors note, however, that a pure resistive load is not useful and a typical load will be a diode rectifier and smoothing capacitor. A further possibility that should be investigated is an active rectifier controlled to draw sinusoidal current and present a resistive characteristic to the transducer.

Lefeuvre et al. have recently designed a power converter for use with piezoelectric generators [170]. In order to maximize the power harvested, the circuitry needs to present an optimal load resistance to the piezoelectric element. In order to achieve this in an efficient way, the authors use a buck-boost converter running in discontinuous mode with a fixed duty cycle. When running in discontinuous mode, the input impedance of a buck-boost converter is resistive (the input current automatically increases in proportion to the input voltage) if the output voltage is held constant (i.e., connected to a battery). This feature of the circuit means that an adaptive control circut is not needed, which reduces the power consumption of the control circuitry. However, if the circuit enters continuous conduction mode, this linear relationship between current and voltage is lost and so a closed-loop controller would be required. Results obtained from the prototype converter give an efficiency of $84 \%$ for input voltages between 1.6 and $5.5 \mathrm{~V}$ and for output powers between $200 \mu \mathrm{W}$ and $1.5 \mathrm{~mW}$.

If a resistive load is connected to a piezoelectric element, maximum power is generated when the resistance of the load is the same as the magnitude of the impedance of the capacitor at the given operating frequency. This can significantly reduce the damping force available from the transducer and the amount of energy that can be dissipated in the load, as much of the energy generated is reactive, being stored in the piezoelectric capacitance. A method to reduce these problems is to use the nonlinear processing technique presented by Guyomar et al. in [171]. In this technique, the polarity of the charge on a piezoelectric element is reversed by ringing the charge through an inductor when the element is in a stressed state. In other words, a cantilever beam is bent in one direction, charging the piezoelectric material with a polarity in which the electric field tries to straighten the beam. Then, the polarity of the charge on the element is reversed, meaning that the electric field direction is such that the beam bends further. This technique allows an increase in the force against which work is done to generate electrical energy. In addition, the energy transfer from the piezoelectric element to load is no longer hampered by the shunt capacitance. It should be noted that this technique does not allow the limits on power generation presented by the linear equation of (5) to be exceeded, but it does allow greater damping forces to be achieved in piezoelectric harvesters and overcomes the limit on power transfer brought about by the existence of the shunt capacitor.

Power electronics for electrostatic microgenerators is considered in [102]. Although two circuit topologies for both constant charge and constant voltage operation are discussed, the work concentrates on the former. The proposed circuit charges and discharges the variable capacitor of the transducer from a reservoir via an inductor using MOSFET switches. Standard commercial MOSFETs of vertical structure were chosen because of their relatively small capacitances. A scaled-up test transducer was built. A simulation model in Matlab allowed circuit and transducer to be modelled with several measured parasitic components included, albeit with approximations such as constant valued MOSFET capacitances. (Simulation in SPICE, which allows accurate circuit simulation, is also possible [172].) Results from the model agree very well with the experimental results. Further work in [102] applied the Matlab model to smaller scale devices, although a relatively large inductor of $1 \mathrm{mH}$ was used in the processing circuit (too large for on-chip integration). The MOSFETs are changed to lateral devices. These are compatible with integrated circuit (IC) and MEMS processes, whereas vertical devices are not, but the claimed benefits of absence of body-drain diode and lower capacitance we believe to be erroneous. The simulation results show that for an energy generated by the moving plate capacitor of around $24 \mathrm{~nJ} /$ cycle, only $0.5 \mathrm{~nJ}$ is transferred to the output (an electrical efficiency of around $2 \%$ ). The author concludes that the parasitic capacitance of the MOSFETs and the series resistance of the inductor are the main contributing factor to the low efficiency, and calculates that if the former could be reduced by a factor of ten, the efficiency of the power electronics would improve to $54 \%$.

In an analysis of power processing circuits for the CFPG, it was shown that the power converter attached to this device needs to have an off-state impedance of more than $10^{12} \Omega$ and less than $1 \mathrm{pF}$ of input capacitance to maintain $80 \%$ of the generated energy [173]. To achieve this high level of impedance, a thin-layer silicon-oninsulator MOSFET was designed. The power converter circuit was then simulated using finite element software, so that the physical effects such as electron-hole pair generation and impact ionization, substrate currents, and 
charge storage could be modelled. Detailed simulation studies were carried out to optimize the MOSFET device area to optimize the energy generated from the system, taking into account conduction loss and charge-sharing effects. The on-state voltage drop of the MOSFET predominantly affects the conversion efficiency because of high peak currents, which are due to the low inductance used in the circuit in order that the inductor could be integratable on chip. It was found that when the MOSFET was replaced by an insulated-gate bipolar transistor (IGBT), the size of the inductor could be reduced by a factor of two while maintaining the same conversion efficiency. Exploiting latch-up in the IGBT was found to give further advantage [174].

In [175], the authors briefly discuss the power processing circuits suitable for the three main transducer types. A dual-polarity boost converter is proposed for the electromagnetic transducer. This is convenient for two reasons: the voltage from the transducer needs to be stepped up in order to power circuitry and the dual polarity nature of the converter removes the need for the voltage drop associated with a bridge rectifier.

There is broader work on low-power on-chip power processing relevant to energy harvesting, such as reported in the special issue on "Integrated Power Electronics" of the IEEE Transactions on Power Electronics in May 2005. For instance, Ó’Mathúna et al. in [176] report work on integrated magnetics and note that integrated inductors, a requirement for on-chip power processing, with values of $1 \mu \mathrm{H}$ and dc resistances less than $150 \mathrm{~m} \Omega$, have been reported. They also note that lateral power MOSFETs (compatible with IC design and MEMS) have been realized with power capabilities comparable to the common vertical power MOSFETs. These are two key technologies for achieving highly efficient on-chip power processing.

\section{COMMERCIALLY AVAILABLE MOTION HARVESTERS}

There are clear application areas for motion-harvesting microgenerators, particularly for wireless sensors, and to meet these a number of commercial offerings have appeared. This is still an immature market, with some companies seeing themselves as pioneers, helping customers understand what such microgenerators can offer. It is also the case that the full range of generator types is not yet available, and some of the offerings are still engineering samples.

The general position is that the power required in many applications is well above that achieved by the microengineered devices that are the focus in much of the research community. The commercial suppliers bridge that gap by offering miniature conventionally engineered generators rather than true MEMS devices. The target applications are those where small size is not a crucial requirement but avoidance of batteries is. Even with these relatively large generators, it has been necessary to target well-characterized narrow-band vibration sources of high amplitude and frequency.

Two companies offering electromagnetic harvesters are Perpetuum and Ferro Solutions. The similarities in their devices are perhaps more evident than their differences. Perpetuum offers devices such as its PMG17 [140] and Ferro Solutions offers the VEH360 [141]. Both are mechanically resonant devices with a relatively narrow bandwidth centered on the frequencies at which electrical machines are supplied, although the PMG17 is tuned to the second harmonic (100 or $120 \mathrm{~Hz}$ ) and the VEH360 to the fundamental ( 50 or $60 \mathrm{~Hz}$ ). The PMG17 is slightly larger at $55 \mathrm{~mm}$ diameter and $55 \mathrm{~mm}$ length against 66 and $39 \mathrm{~mm}$ for the VEH360. The weights are 0.7 and $0.29 \mathrm{~kg}$, respectively. At a source acceleration of $0.1 \mathrm{~g}$, the PMG17 has a stated power of $4.5 \mathrm{~mW}$, while that of the VEH360 is $10.8 \mathrm{~mW}$. However, the former is rectified dc output, while the latter is raw ac into a resistive load; for 3.3 VDC output at $0.1 \mathrm{~g}$, the VEH360 quotes only $2 \mathrm{~mW}$. The PMG17 also has a wider bandwidth at this acceleration, $7 \mathrm{~Hz}$ versus $3 \mathrm{~Hz}$ for the VEH360 (the fractional bandwidth is thus roughly equal). For dc output, both show power approximately proportional to source amplitude. The VEH360 is also offered with a power processing circuit, containing a large storage capacitor that approximately doubles its length. The $\mathrm{FoM}_{V} \mathrm{~s}$ of the PMG17 and VEH360 are recorded in Table 1 and Fig. 26; while the latter is significantly higher, other factors must also be considered, as noted above, including bandwidth, power processing circuitry, and usable input amplitude range.

Vibrations in the $100 \mathrm{~Hz}$ region are also being addressed with the Volture piezoelectric microgenerators offered by Mide. The largest, the PEH20W [159], is $92 \times 44 \times 10 \mathrm{~mm}$, including the power processing circuit. It is a resonant device with a $3 \mathrm{~Hz}$ bandwidth but can be passively tuned (by choice of mass) within the range 50-150 Hz. With $1 \mathrm{~g}$ input excitation, it will produce $8 \mathrm{~mW}$ when tuned to $50 \mathrm{~Hz}$ and $1.8 \mathrm{~mW}$ when tuned to $150 \mathrm{~Hz}$. The energy yield is almost a linear function of acceleration amplitude down to $0.2 \mathrm{~g}$. From a volume of about $30 \%$ of the Perpetuum PMG17, it produces $3.5 \mathrm{~mW}$ at $100 \mathrm{~Hz}$ and $1 \mathrm{~g}$, which is less than $10 \%$ of the corresponding $40 \mathrm{~mW}$ of the PMG17. The $\mathrm{FoM}_{V}$ of the PEH20W (Table 3) varies from $0.16 \%$ at $50 \mathrm{~Hz}$ to $0.012 \%$ at $150 \mathrm{~Hz}$. However, the PEH20W includes the power processing within the package volume. The piezoelectric element without power processing, mounting, proof mass, or case is very small at $50 \times 38 \times 0.76 \mathrm{~mm}$.

Two other piezoelectric devices are worth noting but can not be fully analyzed from publicly available data. Advanced Cerametrics produces microgenerators using fiber composite materials for integrating into clothing or creating complex shapes. ${ }^{2}$ An example with a resonant frequency of $35 \mathrm{~Hz}$ is claimed to yield $145 \mathrm{~mW}$ when

${ }^{2} \mathrm{http} / / /$ www.advancedcerametrics.com/pages/energy_harvesting. 
driven with a force of $4 \mathrm{~N}$, but there are no data available on the device size. EnOcean offers a wireless switch [55] that transmits data with each button press. Pressing the button excites a piezoelectric element that powers the transmitter.

Kinetron offers rotational generators for energy harvesting. These use permanent magnets rotating within coils in a miniature variant of a conventional electrical generator. The smallest device is the MG204 at $4 \mathrm{~mm}$ diameter and $2.2 \mathrm{~mm}$ length [177]. When rotated at $5000 \mathrm{rpm}$, it can generate $10 \mathrm{~mW}$. Direct comparison with the vibration driven generators is difficult because of the difference in movement source. It is offered with a waterdriven turbine, and also with an eccentric mass and spring arrangement that can drive the generator from lowfrequency irregular body movement. For an assumed 4000 revolutions of the mass per day from wrist movement, $400 \mathrm{~mJ}$ can be generated, corresponding to about $5 \mu \mathrm{W}$ average power.

\section{CONCLUSION}

Energy harvesting is a topic of substantial and increasing research attention, and motion-driven devices represent a large fraction of this activity. Motion energy harvesting devices are now offered commercially by several companies, mainly for applications where machine vibration is the motion source, although body-powered applications (particularly body sensor networks) are actively pursued. Fundamental analysis indicates that for body motion in particular, achievable power levels for miniature harvest- ers (below $1 \mathrm{cc}$ ) will reach a few milliwatts at most, thus limiting the range of devices that can be powered. Wireless sensor nodes are the most promising application area for vibration harvesting, with a wide range of application areas and corresponding motion sources.

Reported implementations of energy harvesters are showing progress on miniaturization, and practical MEMS devices are beginning to appear. Piezoelectric, electrostatic, and electromagnetic devices are all widely investigated. Reported power levels are improving but remain well below theoretical maxima. Metrics for comparing device performance are not straightforward to define, with effectiveness providing a more useful concept in this regard than efficiency. Two performance metrics are used in this paper for inertial harvesters: one ("harvester effectiveness") that is relative to the chosen device parameters of mass and internal motion range and one (volume figure-ofmerit) that is relative to the overall volume of the device. Comparisons using these measures show that the highest effectiveness values have been achieved for larger devices, operating in the frequency range $10-100 \mathrm{~Hz}$.

Practical exploitation of harvesting devices depends on having efficient power processing and control circuitry, and consequently electronics for energy harvesting devices is a rapidly growing subtopic of research. Dynamic power optimization solutions (e.g., maximum power point tracking) are beginning to appear. Successful exploitation of motion energy harvesting for many applications is likely to require integrated design of the complete wireless system, including power-aware operation of the powered device.

\section{REFERENCES}

[1] D. Dunn-Rankin, E. M. Leal, and D. Walther, "Personal power systems," Prog. Energy Combust. Sci., vol. 31, no. 5-6, pp. 422-465, 2005.

[2] S. Roundy, P. K. Wright, and J. M. Rabaey, Energy Scavenging for Wireless Sensor Networks, 1st ed. Boston, MA: Kluwer Academic, 2003.

[3] M. Schmidt, "Portable MEMS power sources," in IEEE Int. Solid State Circuits Conf. Dig. Tech. Papers, 2003, pp. 394-395.

[4] K.-S. Chen, S. M. Spearing, and N. N. Nemeth, "Structural design of a silicon micro-turbo generator," Amer. Inst. Aeronaut. Astronaut. J., vol. 39, no. 4 , pp. 720-728, 2001.

[5] N. Nakajima, K. Ogawa, and I. Fujimasa, "Study on micro-engines-Miniaturising stirling engines for actuators and heatpumps," in Proc. Micro Electro Mech. Syst., Salt Lake City, UT, Feb. 1989, pp. 145-148.

[6] S. Yao, X. Tang, C. Hsieh, Y. Alyousef, M. Vladimer, G. K. Fedder, and C. H. Amon, "Micro-electro-mechanical systems (MEMS)-based micro-scale direct methanol fuel cell development," Energy, vol. 31, pp. 636-649, 2006.

[7] S. Kamarudin, W. Daud, S. Ho, and U. Hasran, "Overview on the challenges and developments of micro-direct methanol fuel cells (DMFC)," J. Power Sources, vol. 163, pp. 743-754, 2007.

[8] A. Lewandowski and M. Galinski, "Practical and theoretical limits for electrochemical double-layer capacitors," J. Power Sources, vol. 173, no. 2, pp. 822-828, 2007.

[9] A. Lal and J. Blanchard, "The daintiest dynamos," IEEE Spectrum, pp. 36-41, Sep. 2004.

[10] S. Roundy, D. Steingart, L. Frechette, P. Wright, and J. Rabaey, "Power sources for wireless sensor nodes," Lecture Notes in Computer Science, vol. 2920/2004, pp. 1-17, Jan. 2004.

[11] T. Fukunda and W. Menz, Eds., Handbook of Sensors and Actuators, 1st ed. Amsterdam, The Netherlands: Elsvier, 1998, vol. 6, ch. 7.

[12] B. Obrist and S. Hegnauer, "A microwave powered data transponder," Sensors Actuators A, Phys., vol. 46, pp. 244-246, 1995.

[13] S. Suzuki, T. Katane, H. Saotome, and O. Saito, "A proposal of electric power generating system for implanted medical devices," IEEE Trans. Magn., vol. 35 pp. 3586-3588, Sep. 1999.

[14] C. Evans-Pughe, "Close encounters of the magnetic kind," Inst. Elect. Eng. Rev. vol. 51, no. 5, May 2005.
[15] R. Want, K. I. Farcas, and C. Narayanaswami, Eds., Pervasive Comput., vol. 4, Jan.-Mar. 2005.

[16] W. Clark, Ed., J. Intell. Mater. Syst. Struct., vol. 16, p. 783, 2005.

[17] J. B. Lee, Z. Chen, M. G. Allen, A. Rohatgi, and R. Arya, "A high voltage solar cell array as an electrostatic MEMS power supply," in Proc. IEEE Workshop Micro Electro Mech. Syst., 1994, pp. 331-336.

[18] D. M. Bennett, R. H. Selfridge, and P. Humble, "Hybrid power systems for autonomous MEMS," in Proc. SPIE Smart Struct. Mater., 2001, vol. 4334, pp. 354-362.

[19] K. Sangani, "Power solar-The sun in your pocket," Eng. Technol., vol. 2, no. 8, pp. 36-38, Aug. 2007.

[20] H. Böttner, "Thermoelectric micro devices: Current state, recent developments and future aspects for technological progress and applications," in Proc. 21st Int. Conf. Thermoelect., Aug. 2002, pp. 511-518.

[21] M. Strasser, R. Aigner, C. Lauterbach, T. F. Sturm, M. Franosch, and G. Wachutka, "Micromachined CMOS thermoelectric generators as on-chip power supply," in Proc. Transducers '03, Boston, MA, Jun. 2003, pp. $45-48$.

[22] M. Stordeur and I. Stark, "Low power thermoelectric generator-Self-sufficient energy supply for micro systems," in Proc. 
16th Int. Conf. Thermoelect., Aug. 1997, pp. 575-577.

[23] R. Venkatasubramanian, C. Watkins, D. Stokes, J. Posthill, and C. Caylor, "Energy harvesting for electronics with thermoelectric devices using nanoscale materials," in IEEE Int. Electron Devices Meeting, Dec. 2007, pp. 367-370.

[24] M. H. Mickle, M. Lovell, L. Mats, L. Neureuter, and D. Gorodetsky, "Energy harvesting profiles, and potential sources," Int. J. Parallel Distrib. Syst. Netw. vol. 4, no. 3, pp. 150-160, 2001.

[25] M. Philipose, J. R. Smith, B. Jiang, A. Mamishev, S. Roy, and K. Sundara-Rajan, "Battery-free wireless identification and sensing," Pervasive Comput., vol. 4, pp. 37-45, Jan.-Mar. 2005.

[26] E. D. Mantiply, K. R. Pohl, S. W. Poppell, and J. Murphy, "Summary of measured radiofrequency electric and magnetic fields $(10 \mathrm{kHz}$ to $30 \mathrm{GHz})$ in the general and work environment," Bioelectromagnetics, vol. 18, no. 8, pp. 563-577, 1997.

[27] G. Justin, M. Sun, Y. Zhang, X. Cui, and R. Sclabassi, "Serotonin (5-ht) released by activated white blood cells in a biological fuel cell provide a potential energy source for electricity generation," in Proc. IEEE 28th Annu. Int. Conf. Eng. Med. Biol. Soc. (EMBS '06), Aug. 2006, pp. 4115-4118.

[28] F. Moll and A. Rubio, "An approach to the analysis of wearable body-powered systems," in Proc. Mixed Design Integr. Circuits Syst. Conf., Gdynia, Poland, Jun. 2000.

[29] S. Roundy, P. K. Wright, and J. M. Rabaey, "A study of low level vibrations as a power source for wireless sensor nodes," Comput. Commun., vol. 26, pp. 1131-1144, 2003.

[30] T. Starner and J. A. Paradiso, "Human generated power for mobile electronics," in Low-Power Electronics Design, C. Piquet, Ed. Boca Raton, FL: CRC Press, 2004, pp. 1-35.

[31] T. Starner, "Human powered wearable computing," IBM Syst. J., vol. 35, no. 3-4, pp. 618-629, 1996.

[32] D. Wanless, "Securing our future health: Taking a long term view," HM Treasury, U.K., Apr. 2002, Tech. Rep.

[33] A. Flowerday and R. Smith, "Lessons learnt from long-term chronic condition monitoring," in Proc. 1st Int. Workshop Wearable Implantable Body Sensor Netw., Imperial College London, U.K., Apr. 2004, p. 48.

[34] P. Needham and L. Gamlyn, "Arrhythmia analysis in the community," in Proc. 1st Int. Workshop Wearable Implantable Body Sensor Netw., Imperial College London, U.K. Apr. 2004, pp. 49-50.

[35] A. Heller, "Drug delivering integrated theraputic systems," in Proc. 2nd Int. Workshop Wearable Implantable Body Sensor Netw., Imperial College London, South Kensington, London, U.K., Apr. 2005, pp. 6-11.

[36] B. B. Owens, Batteries for Implantable Biomedical Devices. New York: Plenum, 1986.

[37] P. Bauer, M. Sichitiu, R. Istepanian, and K. Premaratne, "The mobile patient: Wireless distributed sensor networks for patient monitoring and care," in Proc. Int. Conf. Inf. Technol. Applicat. Biomed. (EMBS), Arlington, VA, Nov. 2000, pp. 17-21.

[38] B. P. L. Lo and G. Z. Yang, "Key technical challenges and current implementation of body sensor networks," in 2nd Int. Workshop
Wearable Implantable Body Sensor Netw., Imperial College London, South Kensington, London, U.K., Apr. 2005, pp. 1-5.

[39] G. Görge, M. Kirstein, and R. Erbel, "Microgenerators for energy autarkic pacemakers and defibrillators: Fact or fiction?" Herz, vol. 26, no. 1, pp. 64-68, Feb. 2001.

[40] M. G. Allen, "Implantable micromachined wireless pressure sensors: Approach and clinical demonstration," in Proc. 2nd Int. Workshop Wearable Implantable Body Sensor Netw., Imperial College London, South Kensington, U.K., Apr. 2005, pp. 40-43.

[41] P. Ross, "Managing care through the air," IEEE Spectrum, vol. 41, pp. 26-31, Dec. 2004.

[42] Proc. 1st Int. Workshop Wearable and Implantable Body Sensor Networks, London, U.K., Apr. 2004. [Online]. Available: http:// vip.doc.imperial.ac.uk/bsn

[43] G. Z. Yang, Ed., Proc. 2nd Int. Workshop Wearable Implantable Body Sensor Netw., London, U.K., Apr. 2005.

[44] E. M. Yeatman, "Advances in power sources for wireless sensor nodes," in Proc. Int. Workshop Wearable Implantable Body Sensor Netw., Imperial College London, U.K., Apr. 2004, pp. 20-21.

[45] G. Asada, M. Dong, T. S. Lin, L. F. Newberg, G. Pottie, and W. J. Kaiser, "Wireless integrated network sensors: Low power systems on a chip," in Proc. Eur. Solid State Circuits Conf., Sep. 1998, pp. 9-16.

[46] K. Bult, A. Burstein, D. Chang, M. Dong, M. Fielding, E. Kruglick, J. Ho, F. Lin, T. H. Lin, W. J. Kaiser, H. Marcy, R. Mukai, P. Nelson, F. L. Newburg, K. S. J. Pister, G. Pottie, H. Sanchez, K. Sohrabi, O. M. Stafsudd, K. B. Tan, G. Yung, S. Xue, and J. Yao, "Low power systems for wireless microsensors," in Proc. Int. Symp. Low Power Electron. Design, Aug. 1996, pp. 17-21.

[47] Microstrain Inc., Strain energy harvesting for wireless sensor networks, Apr. 29, 2005. [Online]. Available: http://www.microstrain. com/white-strain-energy-harvesting.aspx

[48] L. Joselyn, "I think, therefore I interact," New Electron. Campus, pp. 8-10, Autumn 2002.

[49] L. Doherty, B. A. Warneke, B. E. Boser, and K. S. J. Pister, "Energy and performance considerations for smart dust," Int. J. Parallel Distrib. Syst. Netw., vol. 4, no. 3, pp. 121-133, 2001.

[50] H. Bai, M. Atiquzzaman, and D. Lilja, "Wireless sensor network for aircraft health monitoring," in Proc. 1st Int. Conf. Broadband Netw., Oct. 2004, pp. 748-750.

[51] P. A. Garango, D. H. Gilmore, F. A. Pace, and L. Weinstein, "Personal tracking and recovery system," U.S. Patent 5629678 , May 1997.

[52] STMicroelectronics, "Ultra-low current $2.4 \mathrm{~V}$ precision analog temperature sensor datasheet," Nov. 2006.

[53] J. Sauerbrey, D. Schmitt-Landsiedel, and R. Thewes, "A $0.5 \mathrm{~V} 1 \mu \mathrm{W}$ successive approximation ADC," IEEE J. Solid-State Circuits, vol. 38, pp. 1261-1265, 2003.

[54] IMEC. (2007, Feb). IMEC realized world first digital UWB transmitter IC for IEEE 802.15.4a. [Online]. Available: http://www.imec.be/ wwwinter/mediacenter/en/UWB_ISSCC2007. shtml

[55] Ad Hoc Controls. (2008, Jan. 7). Self-powered wireless light control. [Online]. Available: http://www.enocean.com/fileadmin/ redaktion/pdf/tec_docs/datasheet PTM200.pdf

[56] P. D. Mitcheson, T. Sterken, C. He, M. Kiziroglou, E. M. Yeatman, and R. Puers, "Electrostatic microgenerators," Meas. Contr., vol. 41, pp. 114-119, May 2008.

[57] L. Solymar and D. Walsh, Lectures on the Electrical Properties of Materials, 5th ed. Oxford, U.K.: Oxford Univ. Press, 1993.

[58] L. Wang and F. G. Yuan, "Vibration energy harvesting by magnetostrictive material," Smart Mater. Struct., vol. 17, no. 4, pp. 1-10, 2008, art. 45009.

[59] P. Niu, P. Chapman, R. Reimer, and $\mathrm{X}$. Zhang, "Evaluation of motions and actuation methods for biomechanical energy harvesting," in Proc. 35th Annu. IEEE Power Electron. Specialists Conf., Aachen, Germany, Jun. 2004, pp. 2100-2106.

[60] T. Von Büren, P. Lukowicz, and G. Troster, "Kinetic energy powered computing-An experimental feasibility study," in Proc. 7th IEEE Int. Symp. Wearable Comput., White Plains, New York, Oct. 2003, pp. 22-24.

[61] E. M. Yeatman, P. D. Mitcheson, and A. S. Holmes, "Micro-engineered devices for motion energy harvesting," in IEEE Int. Electron Devices Meeting, Washington, DC, Dec. 2007, pp. 375-378.

[62] P. D. Mitcheson, T. C. Green, E. M. Yeatman, and A. S. Holmes, "Architectures for vibration-driven micropower generators," J. Microelectromech. Syst., vol. 13, pp. 429-440, Jun. 2004.

[63] T. Von Büren, P. D. Mitcheson, T. C. Green, E. M. Yeatman, A. S. Holmes, and G. Troster, "Optimization of Inertial Micropower Generators for Human Walking Motion," IEEE Sensors Journal, vol. 6, no. 1, pp. 28-38, 2006.

[64] E. Halvorsen, "Broadband excitation of resonant energy harvesters," in Proc. PowerMEMS 2007, Freiberg, Germany, Nov. 2007, pp. 319-322.

[65] T. Petropoulos, E. M. Yeatman, and P. Mitcheson, "MEMS coupled generators for power generation and sensing," in Proc. Micromech. Europe, Leuven, Belgium, Sep. 2004, pp. 5-7.

[66] S. Roundy and Y. Zhang, "Toward self-tuning adaptive vibration-based microgenerators," in Proc. SPIE, Smart Structures, Devices Syst. II, Feb. 2005, vol. 5649, pp. 373-384.

[67] V. R. Challa, M. G. Prasad, Y. Shi, and F. T. Fisher, "A vibration energy harvesting device with bidirectional resonance frequency tunability," Smart Mater. Struct., vol. 17, pp. 1-10, 2008.

[68] E. M. Yeatman, "Energy harvesting from motion using rotating and gyroscopic proof masses," J. Mech. Eng. Sci., vol. 222, pp. 27-36, 2008.

[69] T. T. Toh, A. Bansal, G. Hong, P. D. Mitcheson, A. S. Holmes, and E. M. Yeatman, "Energy harvesting from rotating structures," in Proc. PowerMEMS 2007, Freiberg, Germany, Nov. 2007, pp. 327-330.

[70] P. D. Mitcheson, E. Reilly, T. Toh, P. Wright, and E. M. Yeatman, "Performance limits of the three MEMS inertial energy generator transduction types," J. Micromech. Microeng., vol. 17, pp. S211-S216, 2007.

[71] S. P. Beeby, M. J. Tudor, and N. M. White, "Energy harvesting vibration sources for microsystems applications," Meas. Sci. Technol., vol. 17, pp. R175-R195, 2006. 
[72] C. C. Enger, "Implantable biotelemetry transmitter and method of using same," U.S. Patent 4177 800, Dec. 1979.

[73] M. Umeda, K. Nakamura, and S. Ueha, "Analysis of the transformation of mechanical impact energy to electric energy using piezoelectric vibrator," Jpn. J. Appl. Phys., vol. 35, no. 5B, pp. 3267-3273, May 1996.

[74] J. L. González, A. Rubio, and F. Moll, "A prospect on the use of piezoelectric effect to supply power to wearable electronic devices," in Proc. Int. Conf. Intell. Robots Syst., Akita, Japan, Oct. 2001, vol. 1, pp. 202-207.

[75] J. L. González, A. Rubio, and F. Moll, "Human powered piezoelectric batteries to supply power to wearable electronic devices," Int. J. Soc. Mater. Eng. Resources, vol. 10, no. 1, pp. 34-40, Mar. 2002.

[76] J. Kymissis, C. Kendall, J. Paradiso, and N. Gershenfeld, "Parasitic power harvesting in shoes," in Dig. Tech. Papers 2nd Int. Symp. Wearable Comput., 1998, pp. 132-139.

[77] N. A. Shenck and J. A. Paradiso, "Energy scavenging with shoe mounted piezoelectrics," IEEE Micro, vol. 21, pp. 30-42, May-Jun. 2001.

[78] N. S. Shenck, "A demonstration of useful electrical energy generation from piezoelectrics in a shoe," Master's thesis, Media Lab, Massachusetts Inst. of Technol. Cambridge, May 1999

[79] H. W. Kim, A. Batra, S. Priya, K. Uchino, and D. Markley, "Energy harvesting using a piezoelectric 'Cymbal' transducer in dynamic environment," Jpn. J. Appl. Phys. vol. 43, no. 9A, pp. 6178-6183, 2004.

[80] F. Lu, H. P. Lee, and S. Lim, "Modelling and analysis of micro piezoelectric power generators for micro-electromechanicalsystems applications," Smart Mater. Struct. vol. 13, pp. 57-63, 2004.

[81] M. J. Ramsay and W. W. Clark, "Piezoelectric energy harvesting for bio MEMS applications," in Proc. SPIE, 2001, vol. 4332, pp. 429-438.

[82] J. M. Donelan, Q. Li, V. Naing, J. A. Hoffer, D. J. Weber, and A. D. Kuo, "Biomechanical energy harvesting: Generating electricity during walking with minimal user effort," Science, vol. 319, pp. 807-810, 2008.

[83] A. Chapius and E. Jaquet, The History of the Self Winding Watch 1770-1931. Geneva, Switzerland: Roto-Sadag, 1956.

[84] M. Hayakawa, "Electric wristwatch with generator," U.S. Patent 5001 685, Mar. 1991.

[85] J. Tiemann, “Apparatus for converting vibratory motion to electrical energy," U.S. Patent 5578 877, 1996.

[86] C. B. Williams and R. B. Yates, "Analysis of a micro-electric generator for microsystems," in Proc. 8th Int. Conf. Solid-State Sensors Actuators, Eurosensors IX Transducers '95, 1995, vol. 1, pp. 369-372.

[87] W. T. Thomson, Theory of Vibration With Applications, 4th ed. Englewood Cliffs, NJ: Prentice-Hall, 1993.

[88] S. Shearwood and R. B. Yates, "Development of an electromagnetic micro-generator," Electron. Lett., vol. 33, pp. 1883-1884, Oct. 1997.

[89] C. B. Williams, S. Shearwood, M. A. Harradine, P. H. Mellor, T. S. Birch, and R. B. Yates, "Development of an electromagnetic micro-generator," Proc. Inst. Elect. Eng. Circuits, Devices Syst., vol. 148, no. 6, pp. 337-342, Dec. 2001.
[90] R. Amirtharajah and A. P. Chandrakasan, "Self-powered signal processing using vibration-based power generation," IEEE J. Solid-State Circuits, vol. 33, pp. 687-695, May 1998.

[91] W. J. Li, T. C. H. Ho, G. M. H. Chan P. H. W. Leong, and H. Y. Wong, "Infrared signal transmission by a laser-micromachined vibration-induced power generator," in Proc. 43rd IEEE Midwest Symp. Circuits Syst. 2000, Aug. 2000, vol. 1, pp. 236-239.

[92] N. N. H. Ching, H. Y. Wong, W. J. Li, P. H. W. Leong, and Z. Wen, "A laser-micromachined multi-modal resonating power transducer for wireless sensing systems," Sensors Actuators A, Phys., vol. 97-98, pp. 685-690, Apr. 2002.

[93] M. El-Hami, P. Glynne-Jones, E. James, S. Beeby, N. M. White, A. D. Brown, J. N. Ross, and N. Hill, "A new approach towards the design of a vibration-based microelectromechanical generator," in Proc. 14th Eur. Conf. Solid-State Transducers, Eurosensors XIV, Copenhagen, Denmark, Aug. 2000, pp. 483-486.

[94] E. P. James, M. J. Tudor, S. P. Beeby, N. R. Harris, P. Glynne-Jones, J. N. Ross, and N. M. White, "An investigation of self-powered systems for condition monitoring applications," Sensors Actuator A, Phys., vol. 110, pp. 171-176, Feb. 2004.

[95] R. N. Torah, S. P. Beeby, T. J., T. O'Donnell, and S. Roy, "Development of a cantilever beam generator employing vibration energy harvesting," in Proc. 6th Int. Workshop Micro Nanotechnol. Power Generation Energy Conversion Applicat., Berkeley, CA, 2006, pp. 181-184.

[96] C. Saha, T. O’Donnell, H. Loder, S. P. Beeby, and M. J. Tudor, "Optimization of an electromagnetic energy harvesting device," IEEE Trans. Magn., vol. 42, no. 10, pp. 3509-3511, 2006.

[97] L. C. Rome, L. Flynn, E. M. Goldman, and T. D. Yoo, "Generating electricity while walking with loads," Science, vol. 309, pp. 1725-1728, 2005

[98] D. Arnold, "Review of microscale magnetic power generation," IEEE Trans. Magn. vol. 43, pp. 3940-3951, Nov. 2007.

[99] S. Meninger, J. O. Mur-Miranda, R. Amirtharajah, A. P. Chandrakasan, and J. H. Lang, "Vibration-to-electric energy conversion," IEEE Trans.Very Large Scale (VLSI) Syst., vol. 9, no. 1, pp. 64-76 Feb. 2001.

[100] R. Amirtharajah, S. Meninger, J. O. Mur-Miranda, A. P. Chandrakasan, and J. H. Lang, "A micropower programmable DSP powered using a MEMS-based vibration-to-electric energy converter," in Proc. IEEE Int. Conf. Solid State Circuits, 2000 pp. 362-363.

[101] S. Meninger, J. O. Mur-Miranda, R. Amirtharajah, A. Chandrakasan, and J. Lang, "Vibration-to-electric energy conversion," in Proc. Int. Symp. Low Power Electron. Design 1999, Aug. 1999, pp. 48-53.

[102] J. O. Mur-Miranda, "Electrostatic vibration-to-electric energy conversion," Ph.D. dissertation, Massachusetts Inst. of Technol., Cambridge, Feb. 2004.

[103] S. Roundy, P. K. Wright, and K. S. Pister, "Micro-electrostatic vibration-to-electricity converters," in Proc. 2002 ASME Int. Mech. Eng. Congr. Expo., New Orleans, LA, Nov. 2002.

[104] R. Tashiro, N. Kabei, K. Katayama, Y. Ishizuka, F. Tsuboi, and K. Tsuchiya,
"Development of an electrostatic generator that harnesses the motion of a living body," JSME Int. J., ser. C, vol. 43, no. 4 pp. 916-922, 2000.

[105] T. Sterken, P. Fiorini, K. Baert, K. Puers, and G. Borghs, "An electret-based electrostatic $\mu$-generator," in Proc. 12th Int. Conf. Solid State Sensors, Actuators Microsyst. (Transducers), Boston, MA, Jun. 2003, pp. 1291-1294.

[106] T. Sterken, P. Fiorini, K. Baert, G. Borghs, and R. Puers, "Novel design and fabrication of a MEMS electrostatic vibration scavenger," in Proc. PowerMEMS 2004, Kyoto, Japan, Nov. 2004, pp. 18-21.

[107] T. Sterken, P. Fiorini, G. Altena, C. Van Hoof, and R. Puers, "Harvesting energy from vibrations by a micromachined electret generator," in Proc. Int. Solid-State Sensors, Actuators Microsyst. Conf. 2007 (TRANSDUCERS 2007), Jun. 2007 pp. 129-132.

[108] M. Mizuno and D. G. Chetwynd, "Investigation of a resonance microgenerator," J. Micromech. Microeng. vol. 13, pp. 209-216, 2003.

[109] P. Miao, P. D. Mitcheson, A. S. Holmes, E. Yeatman, T. Green, and B. Stark, "MEMS inertial power generators for biomedical applications," Microsyst. Technol. vol. 12, no. 10-11, pp. 1079-1083, Sep. 2006

[110] M. Khbeis, J. McGee, C. Richardson, and R. Ghodssi, "Design of hybrid ambient low frequency, low intensity vibration energy scavenger," in Proc. 6th Int. Workshop Micro Nanotechnol. Power Generation Energy Conversion Applicat., Berkeley, CA, Dec. 2006, pp. 287-290.

[111] G. Despesse, T. Jager, J.-J. Chaillout, J.-M. Leger, and S. Basrour, "Design and fabrication of a new system for vibration energy harvesting," Res. Microelectron. Electron. 2005, vol. 1, pp. 225-228, 2005.

[112] D. S. Snyder, "Vibrating transducer powe supply for use in abnormal tire condition warning systems," U.S. Patent 4384382 May 1983.

[113] D. S. Snyder, "Piezoelectric reed power supply for use in abnormal tire condition warning systems," U.S. Patent 4510484 Apr. 1985.

[114] S. Bush, "Power source scavenges energy from environment," Electron. Weekly, p. 3, Feb. 9, 2005

[115] D. Segal and I. Bransky, "Testing of a piezoelectric generator for in-flight electrical powering of electrical guidance systems," Ferroelectrics, vol. 202, pp. 81-85, 1997.

[116] N. G. Elvin, A. A. Elvin, and M. Spector, "A self-powered mechanical strain energy sensor," Smart Mater. Struct., vol. 10, pp. 293-299, 2001.

[117] H. A. Sodano, G. Park, and D. J. Inman, "Estimation of electric charge output for piezoelectric energy harvesting," Strain, vol. 40, pp. 49-58, 2004.

[118] C. Xu, T. Fiez, and K. Mayaram, "Coupled simulation of circuit and piezoelectric laminates," in Proc. 4th Int. Symp. Quality Electron. Design, San Jose, CA, Mar. 2003, pp. 369-372.

[119] P. Glynne-Jones, S. Beeby, and N. M. White, "Towards a piezoelectric vibration-powered microgenerator," Science, Meas. Technol., vol. 148, pp. 68-72, Mar. 2001.

[120] S. Roundy and P. Wright, "A piezoelectric vibration based generator for wireless electronics," Smart Mater. Struct., vol. 13, pp. 1131-1142, 2004 
[121] S. Roundy, B. P. Otis, Y. Chee, J. Rabaey, and P. Wright, "A 1.9 GHz RF transmit beacon using environmentally scavenged energy," in Proc. Int. Symp. Low Power Electron. Design, Seoul, Korea, Aug. 2003.

[122] S. Roundy, E. S. Leland, J. Baker, E. Carleton, E. Reilly, E. Lai, B. Otis, J. M. Rabaey, V. Sundararajan, and P. K. Wright, "Improving power output for vibration-based energy scavengers," Pervasive Comput., vol. 4, pp. 28-36, Jan.-Mar. 2005.

[123] K. Hammond, E. Lai, E. Leland, S. Mellers, D. Steingart, E. Carleton, B. Reilly, J. Baker, B. Otis, J. Rabaey, D. Culler, and P. Wright, "An integrated node for energy-scavenging, sensing, and data-transmission: Applications in medical diagnostics," in Proc. 2nd Int. Workshop Wearable Implantable Body Sensor Netw., Imperial College London, Apr. 2005.

[124] K. E. Reilly and P. Wright, "Thin film piezoelectric energy scavenging systems for an on chip power supply," in Proc. Int. Workshop Micro Nanotechnol. Power Generation Energy Conversion Applicat. Berkeley, CA, Dec. 2006, pp. 161-164.

[125] Y. C. Shu and I. Lien, "Efficiency of energy conversion for a piezoelectric power harvesting system," J. Micromech. Microeng., vol. 16, pp. 2429-2438, 2006.

[126] S. R. Anton and H. A. Sodano, "A review of power harvesting using piezoelectric materials (2003-2006)," Smart Mater. Struct., vol. 16, pp. R1-R21, 2007.

[127] X. Cao, W.-J. Chiang, Y.-C. King, and Y.-K. Lee, "Electromagnetic energy harvesting circuit with feedforward and feedback dc-dc pwm boost converter for vibration power generator system," IEEE Trans. Power Electron., vol. 22, no. 2, pp. 679-685, 2007.

[128] S. P. Beeby, R. N. Torah, M. J. Tudor, P. Glynne-Jones, T. O’Donnell, C. R. Saha, and S. Roy, "Micro electromagnetic generator for vibration energy harvesting," J. Micromech. Microeng., vol. 17, pp. 1257-1265, 2007.

[129] S. Roundy, "On the effectiveness of vibration-based energy harvesting," J. Intell. Mater. Syst. Struct., vol. 16, no. 10, pp. 809-823, 2005

[130] N. N. H. Ching, G. M. H. Chan, W. J. Li, H. Y. Wong, and P. H. W. Leong, "PCB integrated micro-generator for wireless systems," in Proc. Int. Symp. Smart Struct., Hong Kong SAR, Oct. 2000.

[131] W. J. Li, Z. Wen, P. K. Wong, G. M. H. Chan, and P. H. W. Leong, "A micromachined vibration-induced power generator for low power sensors of robotic systems," in Proc. World Automat. Congr. 8th Int. Symp. Robot. Applicat., Maui, HI, Jun. 2000.

[132] M. El-hami, P. Glynne-Jones, N. M. White, N. Hill, S. Beeby, E. James, A. D. Brown, and J. N. Ross, "Design and fabrication of a new vibration-based electromechanical power generator," Sensors Actuators A, Phys., vol. 92, pp. 335-342, Aug. 2001.

[133] N. N. H. Ching, H. Y. Wong, W. J. Li, P. H. W. Leong, and Z. Wen, "A laser-micromachined vibrational to electrical power transducer for wireless sensing systems," in Proc. 11th Int. Conf. Solid-State Sensors Actuators, Munich, Germany, Jun. 2001.

[134] J. M. H. Lee, S. C. Yuen, W. J. Li, and P. H. W. Leong, "Development of an AA size energy transducer with micro resonators," in Proc. Int. Symp.
Circuits Syst., Bangkok, Thailand, May 2003, vol. 4, pp. 876-879.

[135] P. Glynne-Jones, M. J. Tudor, S. P. Beeby, and N. M. White, "An electromagnetic, vibration-powered generator for intelligent sensor systems," Sensors Actuators A, Phys., vol. 110, pp. 344-349, Feb. 2004

[136] S. Beeby, M. Tudor, E. Koukharenko, N. White, T. O’Donnell, C. Saha, S. Kulkarni, and S. Roy, "Design and performance of a microelectromagnetic vibration powered generator," in 13th Int. Conf. Solid-State Sensors, Actuators Microsyst. Dig. Tech. Papers (TRANSDUCERS '05), 2005, vol. 1 pp. 780-783.

[137] S. P. Beeby, M. J. Tudor, R. N. Torah, E. Koukharenko, S. Roberts, T. O'Donnell, and S. Roy, "Macro and micro scale electromagnetic kinetic energy harvesting generators," in DTIP MEMS MOEMS, Stresa, Italy, 2006

[138] C. Serre, A. Prez-Rodriguez, N. Fondevilla, J. Morante, J. Montserrat, and J. Esteve, "Vibrational energy scavenging with si technology electromagnetic inertial microgenerators," in DTIP MEMS MOEMS, Stresa, Italy, 2006.

[139] W.-S. Huang, K.-E. Tzeng, M.-C. Cheng, and R.-S. Huang, "A silicon MEMS micro power generator for wearable micro devices," $J$. Chin. Inst. Eng., vol. 30, no. 1, pp. 133-140, 2007.

[140] Perpetuum Limited, PMG17 datasheet, Jan. 7, 2008. [Online]. Available: http://www.perpetuum.co.uk/resource/ PMG17-100 dsheet.pdf

[141] Ferro Solutions, VEH360 datasheet, Jan. 7, 2008. [Online]. Available: http://www.ferrosi.com/files/ VEH360_datasheet.pdf

[142] R. Tashiro, N. Kabei, K. Katayama, Y. Ishizuka, F. Tsuboi, and K. Tsuchiya, "Development of an electrostatic generator that harnesses the ventricular wall motion," Jpn. Soc. Artif. Organs, vol. 5, pp. 239-245, 2002.

[143] M. Miyazaki, H. Tanaka, G. Ono, T. Nagano, N. Ohkubo, T. Kawahara, and K. Yano, "Electric-energy generation using variable-capacitive resonator for power-free LSI: Efficiency analysis and fundamental experiment," in Proc. Int. Symp. Low Power Electron. Design, Seoul, Korea, Aug. 2003, pp. 193-198.

[144] Y. Arakawa, Y. Suzuki, and N. Kasagi, "Micro seismic electret generator using electret polymer film," in Proc. 4th Int. Workshop Micro and Nanotechnology for Power Generation and Energy Conversion Applicat. Power MEMS, Kyoto, Japan, Nov. 2004, pp. 187-190.

[145] G. Despesse, J. Chaillout, T. Jager, J. M. Léger, A. Vassilev, S. Basrour, and B. Charlot, "High damping electrostatic system for vibration energy scavenging," in Proc. 2005 Joint Conf. Smart Objects Ambient Intell.-Innov. Context-Aware Services: Usages Technol., Grenoble, France, 2005, pp. 283-286.

[146] B. C. Yen and J. H. Lang, "A variable-capacitance vibration-to-electric energy harvester," IEEE Trans. Circuits Syst. I, Regular Papers, vol. 53, no. 2, pp. 288-295, 2006.

[147] T. Tsutsumino, Y. Suzuki, N. Kasagi, and Y. Sakane, "Seismic power generator using high-performance polymer electret," in Proc. 19th IEEE Int. Conf. Micro Electro
Mech. Syst. (MEMS 2006), Istanbul, Turkey, Dec. 2006, pp. 98-101.

[148] T. Tsutsumino, Y. Suzuki, N. Kasagi, K. Kashiwagi, and Y. Morizawa, "Efficiency evaluation of micro seismic electret power generator," in Proc. 23rd Sensor Symp. Sensors, Micromach. Appl. Syst., Sunport Takamatsu, Kagawa, Japan, 2006, pp. 521-524.

[149] P. Glynne-Jones, M. El-Hami, S. P. Beeby, E. P. James, A. D. Brown, M. Hill, and N. M. White, "A vibration-powered generator for wireless microsystems," in Proc. Int. Symp. Smart Struct. Microsyst., Hong Kong, Oct. 2000.

[150] E. Lefeuvre, A. Badel, C. Richard, L. Petit, and D. Guyomar, "A comparison between several vibration-powered piezoelectric generators for standalone systems," Sensors Actuators A, Phys., vol. 126, no. 2, pp. 405-416, 2006.

[151] E. Lefeuvre, A. Badel, C. Richard, L. Petit, and D. Guyomar, "Optimization of piezoelectric electrical generators powered by random vibrations," in DTIP MEMS MOEMS, Stresa, Italy, 2006, pp. 338-343.

[152] H. Tanaka, G. Ono, T. Nagano, and N. Ohkubo, "Electric power generation using piezoelectric resonator for power-free sensor node," in Proc. IEEE Custom Integr. Circuits Conf., 2005, 2005, pp. 97-100.

[153] H.-B. Fang, J.-q. Liu, Z.-Y. Xu, L. Dong, L. Wang, D. Chen, C. Bing-Chu, and Y. Liu, "Fabrication and performance of MEMS-based piezoelectric power generator for vibration energy harvesting," Microelectron. J., vol. 37, no. 11, pp. 1280-1284, 2006.

[154] N. G. Elvin, N. Lajnef, and A. A. Elvin, "Feasibility of structural monitoring with vibration powered sensors," Smart Mater. Struct., vol. 15, no. 4, pp. 977-986, 2006.

[155] R. Duggirala, R. Polcawich, E. Zakar, M. Dubey, H. Li, and A. Lal, "MEMS radioisotope-powered piezoelectric micro power generator (RPG)," in Proc. IEEE 19th Int. Conf. Micro Electro Mech. Syst. 2006, 2006, pp. 94-97.

[156] Y. Jeon, R. Sood, J.-H. Jeong, and S.-G. Kim, "MEMS power generator with transverse mode thin film PZT," in Sensors Actuators A 2005, vol. 122, no. 1, pp. 16-22.

[157] T. H. Ng and W. H. Liao, "Sensitivity analysis and energy harvesting for a self-powered piezoelectric sensor," $J$ Intell. Mater. Syst. Struct., vol. 16, no. 10 pp. 785-797, 2005.

[158] M. Ferrari, V. Ferrari, D. Marioli, and A. Taroni, "Modeling, fabrication and performance measurements of a piezoelectric energy converter for power harvesting in autonomous microsystems," IEEE Trans. Instrum. Meas., vol. 55, no. 6, pp. 2096-2101, 2006.

[159] Mide. (2008, Jan. 7). PEH20W Datasheet. [Online]. Available: http://www. mide.com/products/volture/peh20w/ peh20w.php

[160] J. Douglas et al., Fluid Mechanics, 5th ed. Harlow, U.K.: Pearson Prentice-Hall, 2005.

[161] P. Lissaman, "Low-Reynolds-number airfoils," Annu. Rev. Fluid Mech., vol. 15, no. 1, pp. 223-239, 1983.

[162] C. C. Federspiel and J. Chen, "Air-powered sensor," in Proc. IEEE Sensors, 2003, vol. 1, pp. 22-25.

[163] D. Rancourt, A. Tabesh, and L. G. Fréchette, "Evaluation of centimeter-scale micro 
wind mills: Aerodynamics and electromagnetic power generation," in Proc. PowerMEMS, Freiburg, Germany, Nov. 2007, pp. 93-96.

[164] R. Myers, M. Vickers, and H. Kim, "Small scale windmill," Appl. Phys. Lett., vol. 90, 2007, paper 054106.

[165] A. S. Holmes, G. Hong, K. R. Pullen, and K. R. Buffard, "Axial-flow microturbine with electromagnetic generator: Design, CFD simulation and prototype demonstration," in Proc. IEEE MEMS, 2004, pp. 568-571.

[166] G. K. Ottman, H. F. Hofmann, and G. A. Lesieutre, "Optimized piezoelectric energy harvesting circuit using step-down converter in discontinuous conduction mode," IEEE Trans. Power Electron. vol. 18, pp. 696-703, Mar. 2003.

[167] G. K. Ottman, H. F. Hofmann, A. C. Bhatt, and G. A. Lesieutre, "Adaptive piezoelectric energy harvesting circuit for wireless remote power supply," IEEE Trans. Power Electron., vol. 17, pp. 669-676, Sep. 2002.

[168] T. Le, J. Han, A. von Jouanne, K. Mayaram, and T. S. Fiez, "Piezoelectric power generation interface ciruits," in Proc. IEEE Custom Integr. Circuits Conf. Sep. 2003, pp. 489-492.

[169] J. Han, A. von Jouanne, T. Le, K. Mayaram, and T. S. Fiez, "Novel power conditioning circuits for piezoelectric micro power generators," in Proc. 19th Annu. IEEE Appl. Power Electron. Conf. Expo., 2004, vol. 3, pp. 1541-1546.

[170] E. Lefeuvre, D. Audigier, and D. Guyomar, "Buck-boost converter for sensorless power optimization of piezoelectric energy harvester," IEEE Trans. Power Electron., vol. 22, pp. 2018-2025, Sep. 2007.

[171] D. Guyomar, A. Badel, E. Lefeuvre, and C. Richard, "Toward energy harvesting using active materials and conversion improvement by nonlinear processing," IEEE Trans. Ultrason., Ferroelectr., Freq. Control, vol. 52, pp. 584-595, Apr. 2005.

[172] G. K. Rao, P. D. Mitcheson, and T. C. Green, "Simulation toolkit for energy scavenging inertial micro power generators," in Proc. PowerMEMS 2007, Freiburg, Germany, Nov. 2007, pp. 137-140.
[173] B. Stark, P. Mitcheson, P. Miao, T. Green, E. Yeatman, and A. Holmes, "Converter circuit design, semiconductor device selection and analysis of parasitics for micropower electrostatic generators," IEEE Trans. Power Electron., vol. 21, no. 1 , pp. 27-37, 2006

[174] B. Stark and T. Green, "Comparison of SOI power device structures in power converters for high-voltage, low-charge electrostatic micro-generators," IEEE Trans. Electron Devices, vol. 52, no. 7 pp. 1640-1648, 2005.

[175] P. D. Mitcheson, T. C. Green, and E. M. Yeatman, "Power processing circuits for electromagnetic, electrostatic and piezoelectric inertial energy scavengers," Microsyst. Technol., vol. 13, pp. 1629-1635, 2007.

[176] S. C. O’Mathúna, T. O’Donnell, N. Wang, and K. Rinne, "Magnetics on silicon: An enabling technology for power supply on chip," IEEE Trans. Power Electron., vol. 20, pp. 585-592, May 2005.

[177] Kinetron. (2008, Jan. 4). MG204 datasheet. [Online]. Available: http://www.kinetron.nl

\section{ABOUT THE AUTHORS}

Paul D. Mitcheson (Member, IEEE) received the M.Eng. degree in electrical and electronic engineering and the Ph.D. degree from Imperial College London, U.K., in 2001 and 2005, respectively.

$\mathrm{He}$ is currently a Lecturer with the Control and Power Research Group, Electrical and Electronic Engineering Department, Imperial College London. He has research interests in micropower generators and their associated power electronics.

Eric M. Yeatman (Senior Member, IEEE) received the B.Sc. degree from Dalhousie University, Halifax, NS, Canada, in 1983 and the Ph.D. degree from Imperial College London, U.K., in 1989.

Since then, he has been a Member of Academic Staff with the Electrical and Electronic Engineering Department, Optical and Semiconductor Devices Group, Imperial College London, currently as Professor of Microengineering and Deputy Head of Group. His research interests include micromechanical actuators and generators, microstructures for optical and radio-frequency applications, and technologies for pervasive sensing.

G. Kondala Rao (Student Member, IEEE) received the M.Technol. degree in power electronics and power systems from I.I.T. Bombay, India, in 2003. He is pursuing the Ph.D. degree at Imperial College London, U.K.

His doctoral work focuses on power processing circuits for microgenerators. He was a Power Supply Design Engineer with APC India Design Centre and Hical Magnetics pvt Ltd. He is currently a Research Assistant with the Control and Power Research Group, Electrical Engineering Department, Imperial College London.
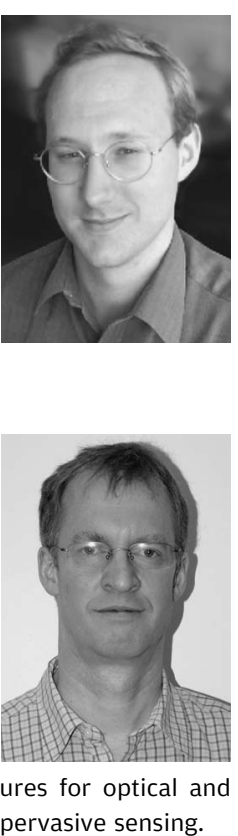

Andrew S. Holmes (Member, IEEE) received the B.A. degree in natural sciences from Cambridge University, Cambridge, U.K., in 1987 and the Ph.D. degree in electrical engineering from Imperial College London, U.K., in 1992.

He is currently Reader in Microelectromechanical systems in the Department of Electrical and Electronic Engineering, Imperial College London. $\mathrm{He}$ is a Cofounder and Director of Microsaic Systems Ltd., a spinout company started in 2001

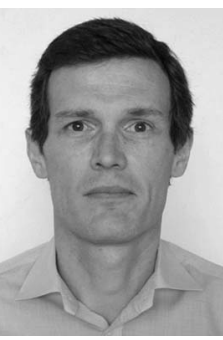
to exploit Imperial College MEMS research. His current research interests lie in the areas of micropower generation and conversion, MEMS devices for microwave applications, and laser processing for MEMS manufacture.

Tim C. Green (Senior Member, IEEE) received the B.Sc. (Eng.) degree from Imperial College London, U.K., in 1986 and the Ph.D. degree in electrical engineering from Heriot-Watt University, U.K., in 1990.

He has been with Imperial College London since 1994, where he is Professor of Electrical Power Engineering and Deputy Head of the Control and Power Research Group. His research interests cover the assessment and integration of

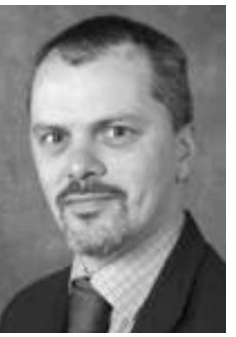
renewable energy sources into electrical networks, distributed generation, power quality and supply quality improvement with distributed generation, the control of flexible ac transmission systems, and power electronics for MEMS microgenerators. He has published 43 journal and more than 100 conference papers. He has held several U.K. government research grants and pursued industrially funded research with ABB, EDF Energy, and National Grid. 